Florida International University FIU Digital Commons

\title{
The Efficacy of an Interactive Computer System for Teaching Developmental Mathematics to College Students
}

Jeffrey Miranda

jmirand2@mdc.edu

DOI: $10.25148 /$ etd.FI14040831

Follow this and additional works at: https://digitalcommons.fiu.edu/etd

Part of the Higher Education Commons

\section{Recommended Citation}

Miranda, Jeffrey, "The Efficacy of an Interactive Computer System for Teaching Developmental Mathematics to College Students" (2014). FIU Electronic Theses and Dissertations. 1148.

https://digitalcommons.fiu.edu/etd/1148

This work is brought to you for free and open access by the University Graduate School at FIU Digital Commons. It has been accepted for inclusion in FIU Electronic Theses and Dissertations by an authorized administrator of FIU Digital Commons. For more information, please contact dcc@fiu.edu. 


\title{
FLORIDA INTERNATIONAL UNIVERSITY
}

Miami, Florida

THE EFFICACY OF AN INTERACTIVE COMPUTER SYSTEM FOR TEACHING

DEVELOPMENTAL MATHEMATICS TO COLLEGE STUDENTS

\author{
A dissertation submitted in partial fulfillment of \\ the requirements for the degree of \\ DOCTOR OF EDUCATION \\ in \\ HIGHER EDUCATION \\ by \\ Jeffrey Miranda
}


To: Dean Delia C. Garcia

College of Education

This dissertation, written by Jeffrey Miranda, and entitled The Efficacy of an Interactive Computer System for Teaching Developmental Mathematics to College Students, having been approved in respect to style and intellectual content, is referred to you for judgment.

We have read this dissertation and recommend that it be approved.

$\begin{array}{r}\hline \text { Maria L. Fernandez } \\ \hline \text { Joy L. Blanchard } \\ \hline \text { Mandayam O. Thirunarayanan } \\ \hline \text { Leonard B. Bliss, Major Professor }\end{array}$

Date of Defense: March 28, 2014

The dissertation of Jeffrey Miranda is approved.

Dean Delia C. Garcia

College of Education

Dean Lakshmi N. Reddi

University Graduate School

Florida International University, 2014 
(C) Copyright 2014 by Jeffrey Miranda

All rights reserved. 


\section{DEDICATION}

I dedicate this dissertation to my late grandmother, Leonor Bravo, who was the most influential person in my education. She taught me to love learning. I also dedicate this dissertation to my late father, Ulises Miranda, who during his short time on this earth showed me so much love. I think of them both every single day of my life. 


\section{ACKNOWLEDGMENTS}

First of all, I would like to thank God for allowing me to experience this great achievement and for letting me meet great people throughout this journey. Second, I would like to thank my committee members, Dr. Maria Fernandez, Dr. Joy Blanchard, Dr. M.O Thirunarayanan, for their insight and support throughout this journey.

Special thanks to my Father-Major-Professor, Dr. Leonard B. Bliss and Dr. Linda Bliss for their unconditional support and patience in helping me achieve this doctorate. Words can't describe how much I appreciate them both.

I would like to also thank my parents, Margarita Bravo and Julio Suarez, for their love and support. They made sure I had the best possible education while I was growing up. Who I am today and everything I have achieved, I owe it all to you both!

To my wife and best friend, I thank you for always being there for me when I needed you the most, especially though out the completion of this dissertation. Thank you for being patient and understanding.

To my tia Nubia Bravo, thank you for taking the risk in bringing me to this country some 28 years ago and for putting up with me for so long. Without you none of this would have happened. This accomplishment is equally yours too.

And finally to all of my former teachers and professors who made an impact and made a difference in my life. I learned so much from each of them. 


\title{
ABSTRACT OF THE DISSERTATION \\ THE EFFICACY OF AN INTERACTIVE COMPUTER SYSTEM FOR TEACHING DEVELOPMENTAL MATHEMATICS TO COLLEGE STUDENTS
}

\author{
by \\ Jeffrey Miranda \\ Florida International University, 2014 \\ Miami, Florida

\section{Professor Leonard B. Bliss, Major Professor}

Many students are entering colleges and universities in the United States underprepared in mathematics. National statistics indicate that only approximately one-third of students in developmental mathematics courses pass. When underprepared students repeatedly enroll in courses that do not count toward their degree, it costs them money and delays graduation. This study investigated a possible solution to this problem: Whether using a particular computer assisted learning strategy combined with using mastery learning techniques improved the overall performance of students in a developmental mathematics course. Participants received one of three teaching strategies: (a) group A was taught using traditional instruction with mastery learning supplemented with computer assisted instruction, (b) group B was taught using traditional instruction supplemented with computer assisted instruction in the absence of mastery learning and, (c) group $\mathrm{C}$ was taught using traditional instruction without mastery learning or computer assisted instruction. Participants were students in MAT1033, a developmental mathematics course at a large public 4-year college. An analysis of covariance using participants' pretest scores as the covariate tested the null hypothesis that there was no significant difference 
in the adjusted mean final examination scores among the three groups. Group A participants had significantly higher adjusted mean posttest score than did group C participants. A chi-square test tested the null hypothesis that there were no significant differences in the proportions of students who passed MAT1033 among the treatment groups. It was found that there was a significant difference in the proportion of students who passed among all three groups, with those in group A having the highest pass rate and those in group $\mathrm{C}$ the lowest. A discriminant factor analysis revealed that time on task correctly predicted the passing status of $89 \%$ of the participants.

It was concluded that the most efficacious strategy for teaching developmental mathematics was through the use of mastery learning supplemented by computer-assisted instruction. In addition, it was noted that time on task was a strong predictor of academic success over and above the predictive ability of a measure of previous knowledge of mathematics. 


\section{TABLE OF CONTENTS}

CHAPTER

PAGE

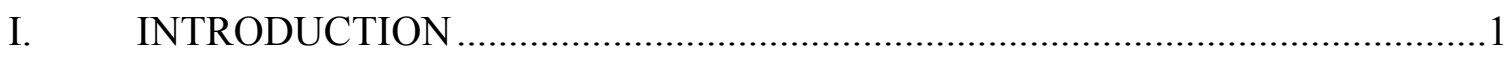

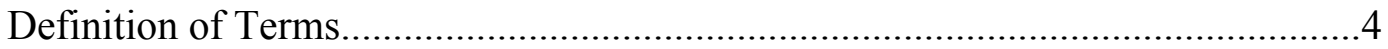

Assumptions, Limitation, and Delimitations of the Study ...................................6

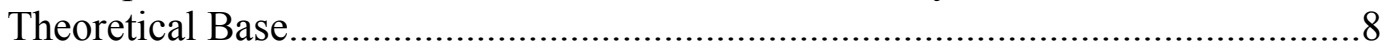

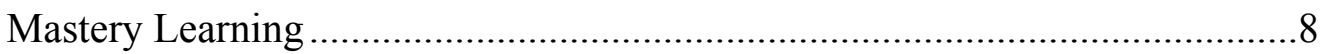

Computer Assisted Instruction....................................................................

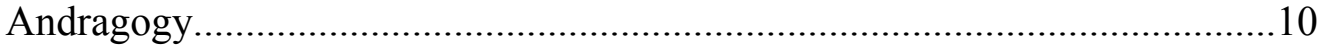

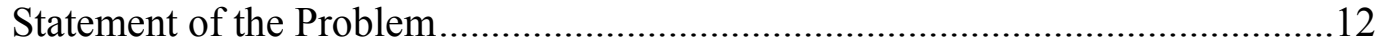

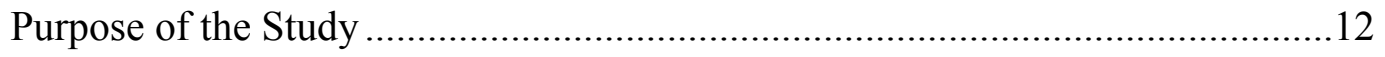

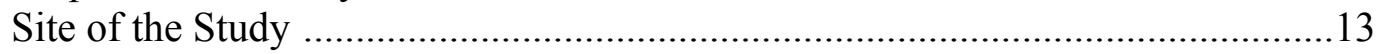

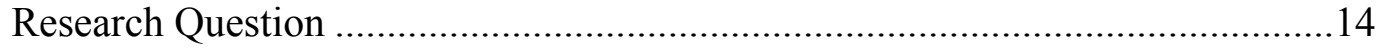

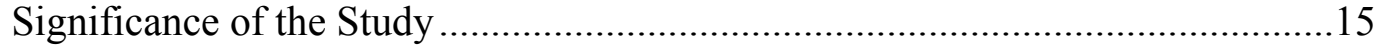

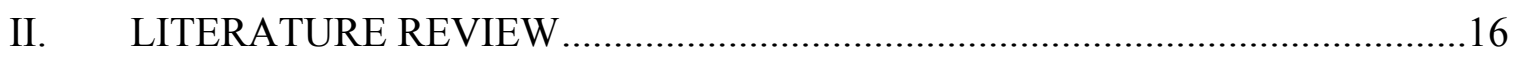

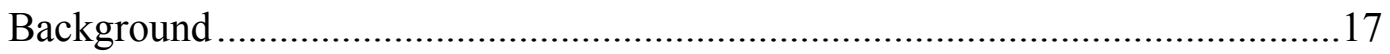

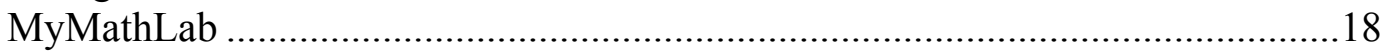

Interactive Tutor Exercise ………………………................................18

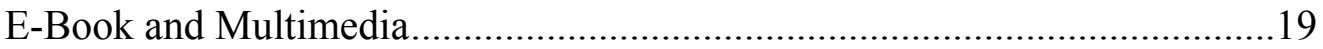

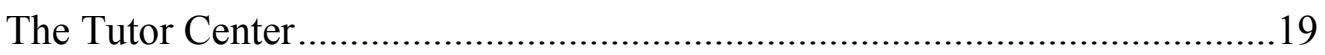

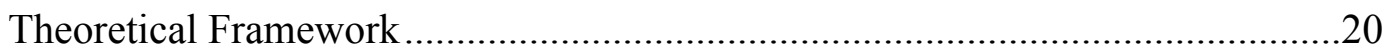

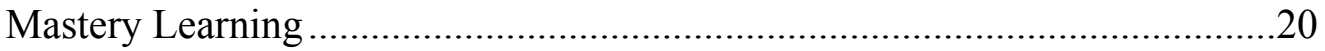

Empirical Findings About Mastery Learning ………………………..............23

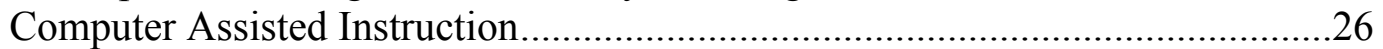

Empirical Findings About Computer Assisted Instruction ...................................28

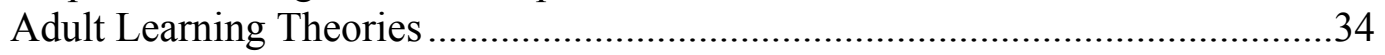

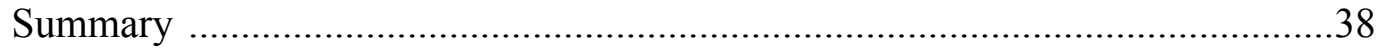

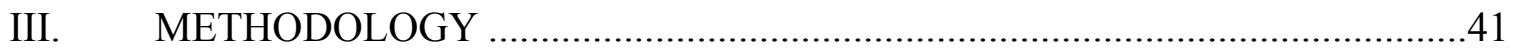

Hypotheses ..................................................................................................

General Research Methodology …………………………..............................43

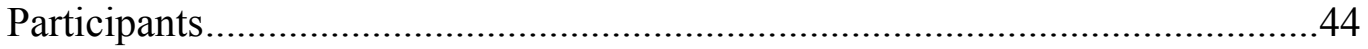

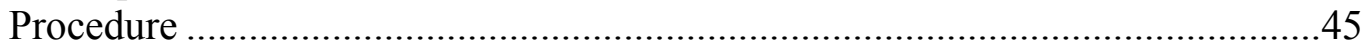

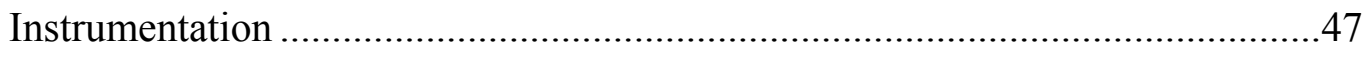

Data Collection and Analysis............................................................................48

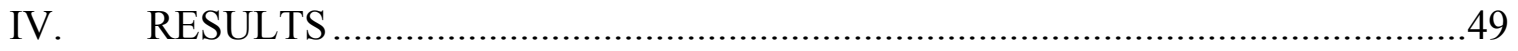

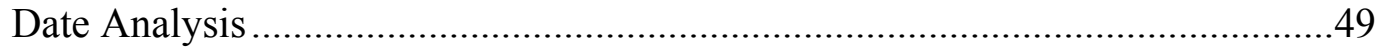

Covarying Only Pretest Scores ..................................................................49

Omnibus Analysis of Covariance ……………………..................................5

Tests of Hypotheses Concerning Group Means.....................................................51

Tests of Hypotheses Concerning Frequencies of Passing Status ...........................53 
Covarying Both Pretest Score and Time on Task ...........................................58

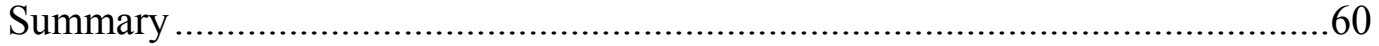

V. DISCUSSION AND RECOMMENDATIONS ...........................................62

Overview of the Problem ........................................................................6. 62

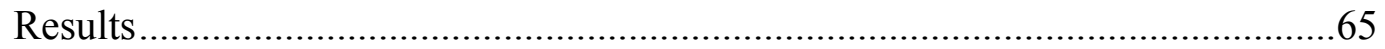

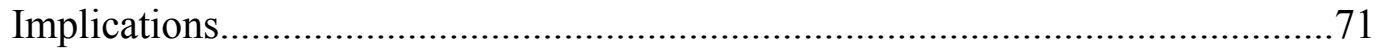

Implications for Practice ......................................................................... 71

Implications for Policy......................................................................... 73

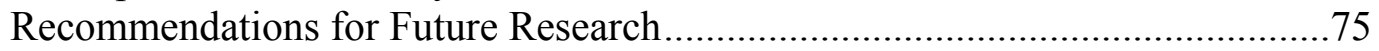

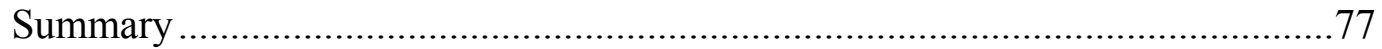

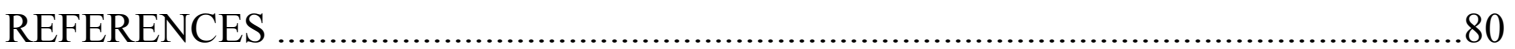

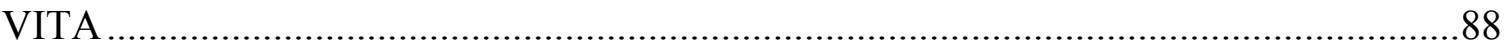




\section{LIST OF TABLES}

TABLE

PAGE

1. Characteristics of the Three Groups ……………..............................................

2. Pretest Descriptive Statistics........................................................................50

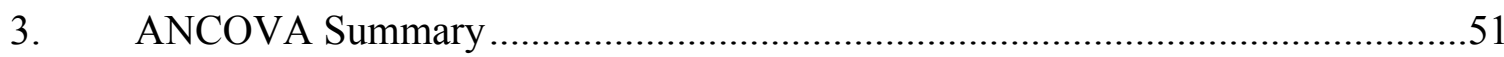

4. Final Examination Posttreatment Scores Adjusted by Pretreatment Scores .........51

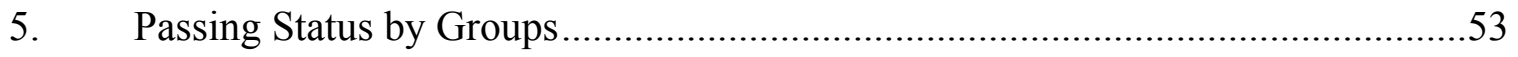

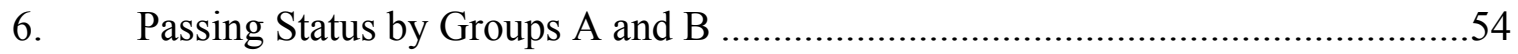

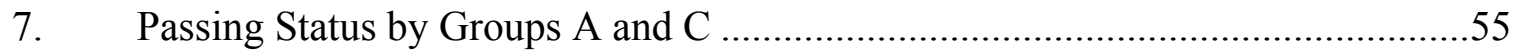

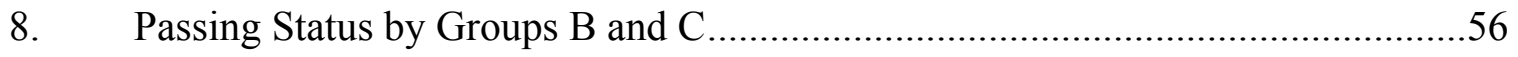

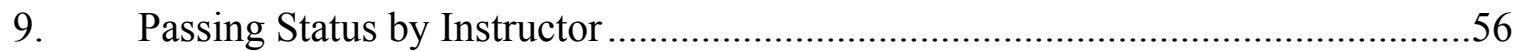

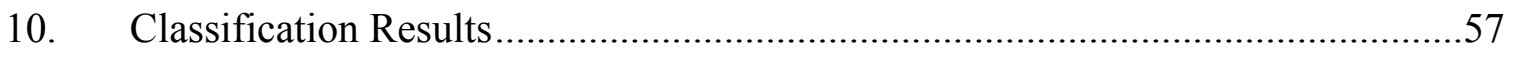

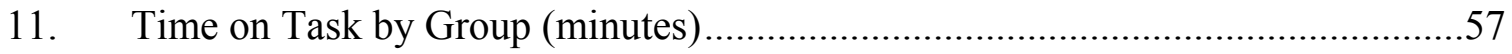

12. Time on Task by Passing Status (minutes) ………............................................57

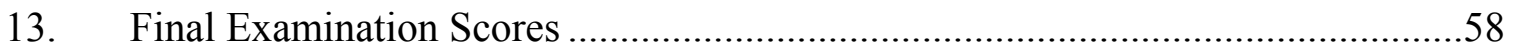

14. Covarying Both Pretest Score and Time on Task...............................59

15. Classification Results using Pretest and Time on Task as Predictors.............60 


\section{CHAPTER I \\ INTRODUCTION}

A great number of students are entering colleges and universities in the United States underprepared in mathematics (Spradlin, 2009). This is a problem for students, schools and the future of the workforce of the U.S. When underprepared students have to enroll in courses that do not count toward their degree, it costs them money and it delays their graduation by one or two years (Business-Higher Education, 2011a). In 2011, 24\% of students in 4-year schools were both interested STEM (Science, Technology, Engineering and Mathematics) related fields and mathematically proficient, compared to only $8 \%$ of those students enrolled in 2-year colleges (Business-Higher Education, 2012). This is critical for the U.S workforce since STEM occupations are projected to grow in the next 10 years by $17 \%$ compared to just over $9 \%$ for other jobs. Furthermore, STEM workers with a bachelor's degree earn $26 \%$ more than their counterparts during the first year after graduation (U.S Department of Commerce, 2011). The root of the problem may start in secondary school where only $17 \%$ of 12 graders were both interested in STEM related fields and mathematically proficient, while $69 \%$ were not interested in STEM related fields (Business-Higher Education, 2011b). The lack of interest in STEM related fields and under-preparation in mathematics represent a threat to the United States' long term global competitiveness in STEM related jobs (Business-Higher Education, 2012).

To address the issue of under-preparation in mathematics, schools offer developmental mathematics courses, where students are placed in order to increase their mathematics achievement to a point where they can be successful in college and university level mathematics classes (Stokes, 2011). During the fall semester of 2000, the 
most current data, over available, $71 \%$ of degree granting institutions offered an average of 2.5 "remedial" courses in mathematics and $98 \%$ of community colleges offered some type of developmental courses, the majority of these developmental courses were in developmental mathematics (Business-Higher Education Forum, 2005). Based on student data from colleges participating in the nationwide Achieving the Dream initiative (www.achievingthedream.org), Bailey and Cho (2010) found that only $31 \%$ successfully completed the sequence of remedial mathematic courses and only $16 \%$ of all students in remedial mathematics went on to complete just one college-level math course within three years. The cost in developmental education costs states and students over one billion dollars a year; students bear most of the financial burden because they have to pay for these remedial classes and it delays their graduation (Bailey \& Cho, 2010).

There is an ongoing debate about whether secondary institutions should offer developmental courses to high school students who should have mastered those basic skills in secondary school. Furthermore, some lawmakers do not want to pay for financial aid for those students enrolled in developmental courses because they consider that taxpayers are paying twice for the same education (Stokes, 2011). Hence professionals, particularly those engaged in public higher education, are challenged to provide strategies for efficient, effective learning, at little or no additional cost to the public, to students who are enrolled in developmental mathematics courses at their institutions. One of the reasons for the need to provide new teaching strategies is that traditional lectures alone have not been a successful teaching mode among developmental students because they do not have the basic skills to succeed in classes that use the lecture format (Boylan \& 
Saxon, 2002). These basic skills include listening, note taking and appropriate study behaviors (Boylan, 2002).

As educators try to find efficacious teaching and learning strategies to better serve developmental mathematics students, computer assisted instruction (CAI) may prove to be a viable solution. Capper and Copple (1985) found (as cited in Stokes, 2011) that students who used CAI learned $40 \%$ faster than those students in traditional lectures. That study also found that students who used CAI performed better on delayed tests than those who did not use CAI. This seems to indicate that students retained more material when CAI was used, compared to students in traditional lectures (Capper \& Copple, as cited in Stokes, 2011). Although many other studies show statistically significant differences in favor of computer assisted instruction over traditional lecture, the best results are from studies where computer assisted instruction was used as a supplement to traditional lectures (Cotton, 1991). This finding is based on an analysis of 59 research reports, 28 were research studies, 22 were reviews, and 9 were meta-analyses research studies.

Earlier research is consistent with Cotton's (1991) findings and recommendations. Suppes and Morningstar (1969) found that computer assisted instruction, specifically the Drill and Practice program, when coupled with regular lecture mode of instruction was more effective among first and six graders in Mississippi and some other elementary school students in California, than those in the control group. Students in the control group had no access to the Drill and Practice problem and were taught through traditional teaching methods. Furthermore, an earlier a meta-analysis pointed to computer assisted instruction as an effective tool to teach mathematics (Kulik, J. \& Kulik, C., 1991). This 
was a meta-analysis of over 250 studies. The authors found that those students who used CAI raised their final examination scores by 0.30 standard deviations. In a more recent meta-analysis of 70 studies on the effectiveness of computer assisted instruction in postsecondary statistics courses with over 40 thousand participants during the past 40 years, the authors reported an overall effect size of 0.566 . These results suggest that a

student who was in the $50^{\text {th }}$ percentile, moved to the $73^{\text {rd }}$ percentile when the student used CAI (Sosa, Berger, Saw, \& Mary, 2011).

According to Cotton (1991), computer assisted instruction is more efficacious when used to supplement traditional lecture than computer assisted instruction alone because students need to see the instructor work out problems and to have the opportunity to ask questions in class in addition to accessing the benefits that CAI offers. Some of those benefits are instant feedback, infinite patience and self-paced learning and videos. This makes CAI an ideal platform for the use of mastery learning in curricula.

\section{Definition of Terms}

Andragogy. The teaching of adult learners (Knowles, 1984).

Adult learner. A person who is 18 years or older who is involved in some form of learning environment (Clark \& Caffarella, 1999).

Computer assisted instruction (CAI). It refers to any computer program that supplements or aids traditional instruction through videos, drill-and-practice, graphics, homework problems, instant feedback, tests, self-pace, and one-to- one interaction 
(Spradlin, 2009). It is common in education for both terms, CBI and CAI, to be used for the same purpose.

Computer based instruction (CBI). A term referring to any type of computer program for educational purposes (Kulik, J., Kulik, C., \& Cohen, 1980).

Computer learning system. A computer software provided by some textbook publishers to complement a textbook. The software includes videos, homework, tests, tutorials, and online tutoring (Spradlin, 2009).

\section{Developmental mathematics (also referred as remedial mathematics). Any} mathematics course taught at the college level (2-year, 4-year or university) below college algebra (www.maa.org).

Failing grade. In this study student grades of $\mathrm{D}$ or $\mathrm{F}$ were considered a failing grade and coded as such for the analysis. Students received a W if they withdrew from the course.

Non-traditional student characteristics. According to the National Center for Education Statistics (2002) non-traditional students have the following characteristics: (a) does not have a high school diploma (completed high school with a GDE or other high school completion certificate or did not finish high school), (b) delays enrollment (does not enter postsecondary the same calendar year that he or she graduated from high school), (c) financially independent for purposes of determining eligibility for financial aid, (d) attend part-time for at least part of the academic year, (e) works full time (35 hour or more per week), (f) has dependent other than a spouse (usually children but sometimes 
others), and (g) is a single parent (either not married or married but separated or has dependent).

Mat1033. A higher education developmental mathematics course that does not meet the mathematics requirements for a postsecondary degree in the state of Florida.

MyMathLab. It is an interactive computer system to may be used to teach mathematics.

Passing grade. In this study student grades of A, B, or C were coded as "passing”.

Traditional college student. Is a student who enrolls full time in postsecondary education right after graduating from high school, depends on parents for financial support, and either does not work during the school year or works part time (National Center for Education Statistics, 2002).

Traditional instruction. Face to face instruction deliver by a teacher dispensing knowledge through lecture sometimes engaging students in discussions and group activities within the classroom (Spradlin, 2009).

Time on task. The time students spent logged into the MyMathLab homework section or in the tutoring laboratory at the college where the study was conducted.

\section{Assumptions, Limitation, and Delimitations of the Study}

Several assumptions have been made for this study. First, I assumed that students enrolled in courses in this study and assigned to sections using MyMathLab had the 
minimum computer stills to use MyMathLab. Second, I assumed that the instructors teaching all courses used in the study had the mathematical knowledge and experience to teach effectively all MAT1033 competencies and objectives. Third, I assumed that all students participating in the study put forth their greatest effort possible to succeed in the course.

There was only one limiting factor in this study. Time on task was defined as the time students spent logged in to MyMathLab homework section or time spent in a tutoring facility at the college. Any time students spent studying outside the college or not in MyMathLab was not recorded as part of time on task for this study.

This study has several delimiting factors. First, this study was conducted at a large public 4-year college in Florida. Second, I used a developmental mathematics course that is taught using three methods of instructions: (a) traditional instruction using mastery learning delivered through by MyMathLab, (b) traditional instruction supplemented by MyMathLab in the absence of mastery learning and (c) traditional instruction alone. Third, all courses in the study used a common pretest and a common final examination (posttest). Fourth, this study was further delimited to traditional and nontraditional college age students who have tested into developmental mathematic courses based on a standardized college placement test. Fifth, all classes participating in the study met during the day and were taught by three full-time faculty who have used MyMathLab in previous terms. Sixth and last, all students in courses in this study using MyMathLab attended a mandatory orientation, run by the computer lab manager, on how to log into 
MyMathLab. Additional instructions on how to use MyMathLab were provided during the first of class by the instructors teaching the courses in this study.

\section{Theoretical Base}

The theoretical base used in this study is informed by theories derived from cognitive psychology, particularly from the parts of the theory concerning mastery learning (Carroll, 1963), from the principles of andragogy (the teaching of adult learners; Knowles, 1984), and the use of computer assisted instruction (Knowlton \& Simms, 2009). MyMathLab's advertised success may be based on two implicit premises: The efficacy of mastery leaning and of computer assisted instruction to improve overall academic achievement of adult learners (Sowell, 2011). Therefore, the use of mastery learning and the use of MyMathLab (MML) were the independent variables examined in this study. They each had two values: (a) use of MML and no use MML during instruction, and (b) use of mastery learning techniques and instruction without mastery learning.

\section{Mastery Learning}

Carroll's model of school learning (1963) led to the development of a mastery learning theory. The main variable behind Carroll's model is time. He stated that each student differs in the amount of time he or she needs to learn a given task. Furthermore, when students are given the time they need and if they persist, they will reach the “criterion level of achievement". He introduced five key variables for school learning, three of which are dependent on time. These are as follows: Aptitude, opportunity to learn, perseverance, ability to understand instruction and quality of instruction. The first 
three are dependent on time on task. The literature suggests that MyMathLab should be an ideal platform for students who may need extra time to practice newly learned material or review previous topics, when needed, without compromising time inside the classroom.

Carroll's (1963) model led to the development of two methods of mastery learning. The first method was Bloom's learning for mastery (1968), which breaks down teaching into small units of instruction; group based, with frequent formative testing, comprehendible instructions and adequate time. The second method was Keller's (1968) personalized system of instruction, which allows students to move through the material at their own pace. One of the common characteristics of the two methods is that students are not allowed to move on to the next unit until they show mastery of the subject area in a particular unit; however, the two methods differ on one teaching strategy. While in Bloom's method students who are struggling in a particular unit are offered assistance in the form of one-on-one tutoring or group study sessions, in Keller's method students are only given the material to learn on their own with little or no assistance from a second party. This study investigates the effectiveness of using mastery learning strategy in classes using MyMathLab as a computer assisted supplement to traditional lecture to facilitate learning based on Bloom's method of mastery learning (1968).

\section{Computer Assisted Instruction}

Nowadays, computer assisted instruction has added an opportunity, in and outside of classrooms, to make teaching and learning mathematics more effective due to easy access from any computer with Internet capabilities. This addresses the "time issue" by allowing students who need extra time to work at their own pace. Computer assisted 
instruction also offers other options such as instant feedback, videos, easy access from a computer with Internet capabilities, guided solutions, and self-paced learning. These are some of the teaching and learning strategies recommended for developmental students since they force students to become engaged in their learning process (Knowlton \& Simms, 2009). In a recent study, students indicated that they learned best when the computer software provided them with videos, instant feedback and a feature called “Help me solve this"(Aichele, Francisco, Utley, \&Wescoatt, 2011).

According to Bloom (1984), computer assisted instruction maybe one of the methods for group instruction as effective as one-on-one tutoring. MyMathLab provides the provision for developing chat rooms where students and instructors can communicate. In a recent study, students strongly agreed that the chat rooms helped them establish a sense of one-on-one tutoring with the instructor (Lu, 2011). Further empirical evidence, discussed in Chapter 2, seems to indicate that computer assisted instruction may be effective when teaching developmental mathematics.

\section{Andragogy}

One of the biggest challenges facing a 2-year institution is the complexity of its student population. A large number of students attending community colleges are consider non-traditional students. According to Galbraith and James (2002/2003), adult learners are unique in their individual characteristics and learning styles. They bring a unique set of qualities to the classroom, including their life experiences, social roles, learning styles and motivation. These are qualities instructors must welcome and embrace. Older students may be adult-parent figures to traditional-age college students. It 
is because of these characteristics of adult students that developmental math instructors need to find better ways to teach college students, especially non-traditional students.

It is very important for instructors to find new teaching and learning strategies to better explain mathematics to adult students. Instructors could use resources such as computer-aided instruction, collaborative learning and lecture with laboratory, to provide adult learners with different teaching and learning styles. Galbraith (2002/2003) suggested that for math instructors to facilitate and to improve learning among adult learners, they must first understand how adult students learn, how to recognize different teaching and learning styles and how to determine what constitutes effective teaching. According to Knowlton and Simms (2009), the best teaching and learning strategies for adult learners are those where students are engaged on their own learning process and have the opportunity to practice newly learned material, constant feedback, and curriculum that facilitates self-paced discovery. MyMathLab provides adult learners with all of these recommended strategies.

Murk (1994) established five "Tested Techniques for Teaching Adults": (a) allow enough time for students to learn the material, (b) create a non-threatening learning environment, (c) get to know your adult learners, (d) allow time to practice new material, and (e) use multi-sensory strategies for learning and remembering material. MyMathLab (MML) addresses four out of these five strategies. When using MML, students will have enough time to review and practice old or new material. Furthermore, MML creates a non-threatening environment by not judging students when they make a mistake. MML provides students with positive instant feedback. MyMathLab allows instructors to get a 
sense of students' weak and strong areas so that a plan of action that will allow the students to learn effectively may be put in place early enough in the semester for it to be efficacious.

\section{Statement of the Problem}

There is a high failure rate among students in developmental mathematics. Two out three community college students placed into remedial mathematics sequence do not complete it and fewer than half of college students enrolled in a "credit-bearing" college mathematics course complete it successfully (Cullinane \& Uri, 2010). This study was under taken to answer the question, will a particular teaching method using mastery learning and supplemented by computer assisted instruction increase levels of achievement and passing rate in developmental mathematics courses over and above teaching methods supplemented by computer assisted instruction where mastery learning is not used, and teaching methods where MyMathLab is not used as a supplement, at all?

\section{Purpose of the Study}

This study examined the effectiveness of mastery learning in a particular developmental mathematics course using a type of computer assisted instruction known as MyMathLab (Pearson, 2013). It was used to supplement traditional instruction in an

effort to improve success rates among developmental mathematics students in a college setting. There were three groups of developmental students. Group A used MyMathLab as a supplement to traditional instruction also using mastery learning, group B used MyMathLab as a supplement to traditional instruction without the use of mastery 
learning, and group $\mathrm{C}$ was taught through traditional instruction only. The three groups were compared using students' final course grades and the passing status (i.e., pass, fail or withdraw).

\section{Site of the Study}

Miami Dade College is the nation's largest Hispanic serving institution with eight campuses in the Miami-Dade area of South Florida. The study took place at Miami Dade College, Homestead campus where during the Fall of 2013. At this time about $64 \%$ of the student body was Hispanic, 19\% was Black Non-Hispanic, and 12\% was White-NonHispanic. Female students represented $62 \%$ of the student population. The average age of the students was approximately 25 years of age with $33 \%$ over the age of 26 . Over twothirds of the student population attended classes part-time (Pousa, 2014). Miami Dade College faced the same challenges and issues faced by other colleges in the U.S. The results of the Miami Dade College mathematics placement test indicated a great need for developmental mathematics courses. Approximately $74 \%$ of incoming students typically showed deficiency in at least one of the three areas: writing, reading and mathematics;

furthermore, $62 \%$ of new arrivals needed remediation in mathematics (Rodriguez, 2011). At Miami Dade College, Homestead Campus, a high percentage of entering students were unprepared for college level mathematics courses based on the scores of the Computerized Placement Tests (CPT). As a result, these students were required to enroll in developmental mathematics courses that did not meet the mathematics requirements for AA or AS degrees. 
At the time this study was carried out Miami Dade College had an open-door admittance policy. As a consequence, many students were non-traditional learners and a large number of them were unprepared for college level courses. Many Miami Dade College students had full time jobs, families, and other responsibilities making it difficult for them to attend classes on a consistent basis resulting in poor academic performance. A large numbers of these students repeated the same mathematic course more than two times in order to take the next mathematics course. They were what the college referred as to as "at risk" students. Unfortunately, many of these "at risk" students give up college during their first year (Bashford, 2006). The literature suggested that Mastery learning coupled with MyMathLab may have been an effective teaching mode for students who may have needed extra time to learn new material through repetition and instant feedback on homework exercises.

\section{Research Question}

The following was the research question of this study: Will a particular teaching method using mastery learning and supplemented by computer assisted instruction increase levels of achievement and students' passing rate in a developmental mathematics course over and above teaching methods supplemented by computer assisted instruction where mastery learning is not used, and a teaching method that is based on lecture and recitation, and does not use MyMathLab as a supplement, at all? 


\section{Significance of the Study}

One of the biggest challenges that community colleges face is developmental education because the majority of incoming students arrive underprepared for "collegelevel" course work, specifically in developmental mathematic where only $30 \%$ of students enrolled in developmental mathematics courses succeed (Bailey,2008). According to a U.S Department of Education study (as cited in Cullinane \& Uri, 2010), the three courses with the highest failure and withdrawal rates in postsecondary education are in all developmental mathematics courses. It has been well documented that developmental students do not do well when they are enrolled in classes taught through traditional instruction only because they do not the necessary skills to succeed in such learning environment (Boylan \& Saxon, 2002; Roueche \& Kirk, 1974).

The literature suggested that a possible strategy to improve success rates among developmental mathematics students may have been a particular teaching strategy called mastery learning delivered through MyMathLab. One of the advantages of mastery learning is that it may break the cycle of failure among those students who struggle the most (Bloom, 1968). In addition, Cotton (1991) noted that computer assisted instruction is more efficacious when it is coupled with traditional instruction than computer assisted instruction alone. This study combined the two teaching strategies and investigated the efficacy of mastery learning delivered through MyMathLab in a particular developmental course (MAT1033) in a college setting. 
CHAPTER II

\section{LITERATURE REVIEW}

Teaching and learning mathematics is a challenge for most mathematics professors and college students. It is important to analyze new teaching and learning strategies that would help college students perform better in mathematics, especially students who have always struggled with mathematics (Li \& Edmonds, 2005).

I believe that teaching mathematics is about the instructors' abilities to explain abstract concepts, which are difficult for most students, and explain them in easy to understand language. Mathematics concepts may be delivered via traditional lesson plans, real life problems, one-on-one tutoring, collaborative learning or computer assisted instruction. It is important that instructors and curriculum developers devise teaching techniques in mathematics and what is essential nowadays is that they explore new teaching and learning strategies along with new technologies available and not just ask "how to do it" but "why to do it" (Winn, 1995). Teaching and learning are not effortless jobs as Galbraith (2002/2003) pointed out: "The mode and complexity of the teaching and learning process are confined in the individuality and idiosyncrasies of those who take on the role of teacher and learner" (p. 9). When this study was undertaken, the literature suggested that a particular mode of instruction, mastery learning, delivered through MyMathLab might make learning more effective for students by providing instant feedback, easy access from any computer with internet access, videos, an e-book, and a system with infinite patience that could supply real world examples. 


\section{Background}

According to Rodriguez (2011), a large number of students were entering Miami Dade College without the skill set to take college level courses, as indicated by the Comprehensive Placement Test. Those students who are not college-ready often end up taking remedial courses, also known as developmental courses. This delays graduations since developmental courses do not satisfy course requirements for associate or bachelors' degrees and the success rate in some of these courses has been as low as 50\% (Bashford, 2006).

One of the reasons why students are not ready for college level mathematics is that they are not taking a sufficient number of mathematic courses in high school. According to Perle, Moran, Lutkus and Tirre, (2005), the percentage of 17-year-olds in the United States who completed courses beyond Algebra 2 was only 17\% in 2004. Nationally, the percentages for Hispanics and Afro-Americans were lower when compared to White students. Only $8 \%$ of Black 17 -year-olds and $14 \%$ of Hispanic 17 year-olds advanced beyond Algebra 2 compared to $19 \%$ of White students. Hawkins, Stancavage, and Dossey (1998) found that in high schools where two years or less of mathematics was required for graduation, $35 \%$ of graduates had completed one year or less of basic algebra.

According to Schwartz (2007), nationally 52\% percent of students entering college need developmental mathematics. To assist these students in becoming successful in math, many colleges have implemented new teaching and learning strategies such as learning-communities, supplemental instruction and computer assisted instruction 
(Schwartz, 2007). Based on their research, Li and Edmonds (2005) have recommended the implementation of computer assisted instruction in mathematics courses since it can facilitate mastery learning, thus helping students who struggle in college mathematics.

This study examined the impact of mastery learning supplemented by a computer assisted instruction, MyMathLab (Sowell, 2011). Specifically, this investigation examined the effectiveness of mastery learning coupled with MML in a college setting on the mathematics achievement of students enrolled in a remedial algebra course, MAT1033.

\section{MyMathLab}

MML is computer software where students have access to features such as interactive tutorial exercises, instant feedback, multimedia, homework, quizzes, tests, videos, e-books and tutorial center. Instructors can assign and monitor students' progress based on homework, quizzes, and tests. A detailed description of some of these features follows below.

\section{Interactive Tutorial Exercise}

Homework and practice exercises are the same as the exercises found in the accompanying text book. The exercises are generated by built-in algorithms to give students unlimited attempts for practice and mastery in a self-paced mode. Exercises come with a step by step guided solution, and when students enter the wrong answer, instant feedback is provided. After the third attempt, a new window with a guided solution appears and a new problem is generated for the student to try again. Students 
also have access to quizzes and tests. This allows for frequent testing which can be monitored by the instructor. Depending on the instructor, these quizzes and tests can be used as part of students' grade or for students to practice newly learned material. Based on students' performance on these quizzes and tests, instructors can create and recommend specific plans of action for each student. Details of these may be found in Chapter 3.

\section{E-Book and Multimedia}

When students $\log$ in to MML, they have access to the same book used in class. In addition to having access to the e-book, students have access to a section called "Tools for Success". In it they find studying and learning techniques, recommendations on how to deal with math anxiety, and how to use graphing calculators. The multimedia section of MML offers a collection of video clips and animations on every section covered in the book. Students can play videos on sections covered by the instructor in class to reinforce learning at a self-paced mode.

\section{The Tutor Center}

Students have access to the Pearson Tutor Center 24 hours a day, 7 days a week. Once registered, students have one free session of up to 30 minutes of one-on-one tutoring for the duration of the course; students can purchase additional hours. They can contact the Tutor Center by phone, fax or email. Assistance is provided in English and Spanish. 


\section{Theoretical Framework}

The theoretical framework used in this study was derived through theories from cognitive psychology, specifically from the theory on mastery learning (Carroll, 1963), from the principles of andragogy (Knowles, 1984), and the use of the use of computer assisted instruction (Knowlton \& Simms, 2009). MyMathLab's reported success may be based on two implicit premises. Although these do not seem to be explicitly identified in any of the literature produced by the publishers or in the very limited professional literature on MyMathLab, they are the efficacy of mastery learning and of computer assisted instruction in producing academic achievement. Therefore, the use of mastery learning, delivered through MyMathLab was the independent variable examined in this study.

\section{Mastery Learning}

Interest in mastery learning dates back to the 1920s but it was not until the 1960s that it gained popularity. Carroll's model of school learning (1963) led to the development of mastery learning theory. The main variable behind Carroll's model is time. Carroll claimed that students differ in the amount of time they need to learn a given task and that when students are given the time they need and if they persist they will reach the "criterion level of achievement". He introduced five key variables for school learning, three of which involve time. He defined each variable as follows.

1. Aptitude is a variable or set of variables that determine the amount of time a student needs to learn a given task, unit of instruction, or curriculum to 
an acceptable criterion of mastery under optimal conditions of instruction and student motivation.

2. Opportunity to learn is defined as the amount of time allowed for learning.

3. Perseverance is defined as the amount of time a student is willing to spend on learning.

4. Quality of instruction refers to the presence of well defined goals for students, coupled with the presence of adequate time and materials for them to reach these goals.

5. Ability to understand instruction refers to the learner's ability to understand what the learning objective is and to determine how to achieve it.

Aptitude, opportunity to learn, and perseverance are all related to time. The use of CAI, specifically MyMathLab provides students with the opportunity to learn 24 hours a day, 7 days per week when using a computer with Internet access.

Learning for mastery. From Carroll's model of learning two methods of mastery learning were developed. The first method was Bloom's learning for mastery (1968), which breaks down teaching into small units of instruction, with frequent formative testing, comprehendible instructions and adequate time. Instructors present the material and students move in a regulated environment. Formative tests serve as a diagnostic tool to help teachers understand students' strengths and weaknesses. Students who reach mastery of the task at hand should be informed that the learning is adequate and should be allowed to move to the next unit. However, Bloom recommended that 
those students who do not achieve mastery should be granted additional time and/or extra assistance in the form of group study or one-on-one tutoring. After these accommodations take place, a second formative test would be given to measure each student's progress. This process is repeated until the student achieves mastery of the task. Bloom claimed that when these learning and teaching strategies are exercised, over $90 \%$ of the students can master the subject. Furthermore, students with low level of ability and knowledge will benefit the most with an instructional program based on mastery learning (Bloom, 1968).

There is much said about mastery learning; however, implementing and applying the theory may be a challenge for some educators. According to Boggs and Shore (2004), instructors using mastery learning face four challenges: (a) creating multiple versions of the each test, (b) grading multiple versions for all students at different stages of the course, (c) scheduling time for students to take different versions of test to assess for particular levels of mastery, and (d) teaching students who are at different levels in the course. Computer assisted instruction is the tool that addresses and facilitates all these four challenges, making mastery learning a practical theory for educators (Vezmar, 2011).

Personalized system of instruction. The second method developed from Carroll's (1963) model of learning was Keller's (1968) personalized system of instruction. Although there are some similarities between the two methods, Keller's method is primarily based on students moving through lessons at their own pace. This strategy allows students to move forward when they can show mastery of a particular 
unit. In some cases students can complete the course before the semester is over. However, students who do not show mastery are required to take a second formative test and work until the material is mastered. Some students may take two semesters to complete the class work typically covered in one semester. Some characteristics of Keller's method for mastery learning include: (a) Proctors' participation, which allows repeated testing, immediate scoring, feedback and tutoring, (b) Lectures and demonstrations that are tools for motivation rather than sources of critical information, and (c) Lessons that are presented by written materials.

\section{Empirical Findings About Mastery Learning}

In 1990, Kulik, J., Kulik, C., and Bangert-Drowns conducted a meta-analysis of 108 studies. These studies involved classes in mathematics, science and social science in colleges, high schools, and the upper grades in elementary schools. A total of 38 studies used Bloom's learning for mastery (LFM) and the rest used Keller's personalized system of instruction (PSI). A total of 103 of the 108 studies provided results from final examinations. By and large, 96 of the 103 studies reported positive results on final examinations for mastery learning. The average effect size in the 103 studies was $d=$ 0.52, which is considered a "medium" effect size. Also, the average student in the control group performed at the $50^{\text {th }}$ percentile whereas the average student in the experimental group performed at the $70^{\text {th }}$ percentile (Kulik, et al.). Although both LFM and PSI reported similar achievement, LFM had higher gains, 0.78 standard deviations $(S D)$, compared to 0.49 standard deviations using PSI. 
Guskey and Gates (1985) performed a meta-analysis of 38 studies on Learning for Mastery using "locally developed criterion tests" to evaluate student achievement from kindergarten through college in many subject areas including mathematics. A total of 35 of the 38 studies reported positive results. The average effect size for achievement gains was $0.94 S D$ for the elementary level, $0.72 S D$ for high school level, and $0.65 S D$ for college level. The average effect size for mathematics was $0.72 S D$. All of these effect sizes were considered to be medium to large.

Abadir (1993) conducted a study on the effectiveness of mastery learning strategies using instructional videos to teach mathematics and individualized instruction, and traditional lecture with a sample of 219 freshmen, all of whom were enrolled in a basic skills mathematics course. Instructional videos in mathematics are designed to help students reach mathematics objectives by presenting a limited amount of content at a given time (a strategy consisted with mastery learning). The student sample was composed of 82 traditional age students and 137 non-traditional age students. The experimental group (109 students) was taught using mastery learning strategies which breaks down teaching into small units of instruction, with frequent formative testing, comprehendible instructions, adequate time, and videos. The control group was taught by traditional lecture mode (110 students). The mastery learning method had a significant main effect on students' achievement as measured by the adjusted posttest means. Furthermore, non-traditional students in the experimental and control groups, performed better than traditional students in both groups. The author suggests that this higher achievement by non-traditional students was due to the fact that in most cases adult 
students have defined goals based on their work experiences (Abadir, 1993). These defined goals or clear objectives are the reason why non-traditional learners tend to be more motivated than traditional students (Cross, 1981).

Boggs and Shore (2004) conducted a study to measure the effectiveness of an eplatform (Blackboard) to teach mathematics using mastery learning strategies. Through Blackboard, students were able to get instant feedback on quizzes, moved through the course's material at their own pace, and had access to chat rooms where they received assistance, if needed, from other classmates and/or the instructor teaching the class. With the use of Blackboard, instructors were able to monitor students' progress through the course and provide help to those students who needed the most assistance through specific homework exercises. The success rate of students in the experimental group was $65 \%$ percent ( $n=40$ students) versus $55 \%(n=220$ students) in the control group. The authors failed to mention whether these results were statistically significant. Students in the experimental group attributed the difference in the success rate on the fact that they were able to do their homework at their own time and place. On the other hand, faculty members were able to create different versions of test for students at different levels in the course. Blackboard made it easy for faculty to assign and grade tests. All of these tools and strategies are ideal setting for teaching developmental mathematics using a mastery learning model (Boggs \& Shore, 2004).

Others have taught using mastery learning in combination with other teaching strategies such as cooperative learning and computer assisted instruction. Hoon, Chong, and Binti Ngah (2010) compared the gain scores and time on task of students taught 
using computer assisted mastery learning (CML), computer assisted cooperative learning (CCL), and computer assisted cooperative mastery learning (CCLM). The sample size was 262 high school students who were learning how to solve matrices. Two groups were formed and taught using the three treatments mentioned above: (a) the first group was with students with low academic ability and (b) the second group was formed with students with high academic ability. They found that the gain scores and time on task were significantly different among the three treatment groups (univariate ANOVA for gain scores, $F=20.155, p<.025$ and time on task, $F=36.066, p<.025)$. Further analysis revealed that there was a significant difference on students' gains scores and time on task between students with low academic ability taught using CCML and CCL. Furthermore, there was a significant difference on students' gain scores between students taught using CML and CCL. Finally, there was significant difference on time on task between students who were taught using CCML and CML. There was no significant difference on students' gains scored among students in all three treatment groups who were labeled with high academic ability; however, there was a significant difference on time on task $\left(\right.$ Time $\left._{\mathrm{CCML}}>\mathrm{Time}_{\mathrm{CML}}>\mathrm{Time}_{\mathrm{CCL}}\right)$. In that study it was not explained what parameters were used to place students into low and high academic ability groups.

\section{Computer Assisted Instruction}

In the 1960s computer-assisted instruction was utilized to drill, tutor, and test students (Kulik, J., \& Kulik, C., 1991). As a result of technological advances, computerassisted instruction has gained popularity since computers have become less expensive and more powerful, which allows students more access to computers at home and at 
schools (Rapaport \& Savard, 1980). Computer-assisted instruction makes it easier for instructors to develop courses that incorporate mastery learning or personalize instruction which may potentially increase passing and retention rates (Trenholm, 2006).

Computer-assisted instruction may be used as an alternative to traditional instruction providing individualized, self-paced instruction or it may be used to supplement traditional instruction to facilitate mastery learning. Computer-assisted instruction has great potential for developmental courses because students can work at their own pace, obtain immediate feedback and have access to practice problems. This makes it ideal for mastery learning (Kinney, 2001).According to Roueche and Kirk (1974), traditional lectures are not adequate for developmental students since they do not have the reading and listening skills. Developmental students learn best by being active learners, (Boylan, 2002). CAI provides the necessary tool to help at risk students become active learners hence achieving mastery learning (Li \& Edmonds, 2005).

Computer-assisted instruction software comes equipped with tutorials which include guided practice problems, videos, and instant feedback which motivates and encourages students to become active learners (Mahmood, 2006). Software can be developed so that a student cannot advance to the next topic before mastering the one he or she is presently working on. This describes mastery learning. Also, computer-assisted instruction software lends itself to frequent testing and feedback, two aspects of mastery learning. These are two teaching strategies identified by the National Association of Developmental Education as two of the best practices of developmental education (Boylan, 2002). 


\section{Empirical Findings About Computer Assisted Instruction}

There is evidence that computer assisted instruction (CAI) is effective most of the time when used for teaching mathematics in different settings and at different levels. Kulik, J., and Kulik, C., (1991) analyzed results of 254 studies that compared students' passing rates in classes taught using traditional lecture supplemented by computer assisted instruction and traditional lecture alone. They found that those students using CAI raised their final examination scores by 0.30 standard deviations. They concluded that the average student in an average CAI class would perform at the $62 \mathrm{nd}$ percentile on an achievement test, while the average student in a control class (No CAI) would perform at the 50th percentile on the same test.

Earlier Kulik, J., and Kulik, C., (1985) found that there are some studies where computer assisted instruction had no major effect when it was used as a supplement to traditional lecture. They analyzed studies conducted at 101 college and universities on mathematics performance of students using computer assisted instruction as a supplement to traditional instruction compared to traditional instruction without CAI supplementation. It was found that students who used CAI as a supplement to traditional lecture had slightly higher post-test scores ( 0.26 standard deviation in the average study) than those students who were taught only with traditional lecture. These studies were done in the natural and social sciences, and in education.

Most recently Kulik (2002) analyzed 16 studies published on the efficacy of computer assisted instruction in mathematics in the United States and abroad. These studies examined the CAI programs of seven vendors in elementary and middle school 
grades. In all 16 studies, it was found that math scores were at least slightly higher in the groups taught using traditional lecture coupled with $\mathrm{CAI}$ than the groups using traditional lecture alone. Furthermore, in nine of these 16 studies the difference in test scores was large enough (greater than 0.25 ) to be considered statistically and "educationally significant". According to Slavin (as cited in Kulik, 2002), an expert in educational evaluation, effect sizes above 0.25 are large enough to be "educationally significant". The median effect size of all 16 studies was 0.38 . None of these studies were done at the college or university level. There is no indication of the types of software that were used in these studies.

Mahmood (2006) conducted a study at a community college in Texas and found higher mathematics achievement in developmental mathematic classes when computer assisted instruction was used as a supplement to traditional lectures when compared to traditional lecture alone. Mahmood used a practice test in a pretest-posttest quasiexperimental design. Students took this practice test to prepare for an assessment test which places students in developmental or college level courses. Four classes participated in the study with a sample size of 123 students; 60 students were in the experimental group and 63 in the control group. Two classes were taught through traditional instructions supplemented with CAI and two were taught by traditional lectures alone. An analysis of variance was performed on the difference in students' final examination scores. The instrument used for pretest and posttest was the Texas Higher Education practice test, which was developed by four independent committees. It was found that students who were taught using CAI as a supplement to traditional lecture instruction had 
significantly higher scores than those who were taught by traditional instruction alone in Analytical Mathematics classes $F(1,62)=3.99 p<.05$ and Fundamental Mathematics classes $F(1,57)=4.560 p<.05$. Weaknesses in that study are that there is no mention in the report of the research of the type of software used, nor whether the readers were told anything about the characteristics of the teachers who taught the experimental and control groups. My study used a different approach. I measured the efficacy of the use of mastery learning delivered through computer assisted instruction, MyMathLab, among developmental students in a college setting.

Li and Edmonds (2005) conducted a qualitative and quantitative study on the efficacy of computer assisted instruction, based on mastery learning, for at-risk adult learners. A total of 48 students participated in that study. Thirty two of the 48 students were in the treatment group and the rest were taught solely by regular lecture. Students were given pre-assessment tests, monthly exams and a comprehensive final. Based on a $t$ test $(t=0.305, p=0.76)$, it was determined that there was no significant difference between the means of the pre-assessment test for the experimental and control groups. When the final examination scores were compared there was no significant difference between the mean scores of the group using CAI and the control group as indicated by a $t$-test $(t=1.9$, $p=0.066$ ). Qualitative analysis was conducted from field observations, student narrative feedback, and instructor's journal. Based on instructor's observation and students' feedback, when students were taught mathematics using computer assisted instruction, they expressed positive attitude and an increase level of confidence toward learning 
mathematics. Students were more engaged in learning mathematics and were comfortable using technology to learn and solve problems (Li \& Edmonds, 2005).

Kulik and Cohen (1980) performed a meta-analysis of 59 studies that utilized computer assisted instruction (CAI). The study reported a modest gain of 0.25 standard deviation units on examinations for advanced learners who used CAI on college-level courses. Furthermore, students reported to have more positive attitudes towards courses that were taught with computers. In addition, instruction time was reduced by two thirds when CAI was used.

Villarreal (2003) conducted a study to measure the difference in pass rates in developmental mathematics at a university. Group A had access to CAI combined with traditional lecture and group B had access to CAI only. With students in group B, the instructor served as guide to assist students with questions, no lecture was provided. It was found that students in group A improved their pass rates by $12 \%$ compared to students in group B. However, it was not reported whether these represented statistically significant differences. Some of the issues noticed in group B were the lack of motivation displayed by the student, unwillingness to read the book, solely relying on private or school's tutors to teach them the material and lacked of basic computer skills. These results seem to be consistent with earlier research that indicates that developmental students benefit the most when CAI is use to supplement traditional lectures (Boylan, 2002). Based on the results from Villarreal's study, it appears that most developmental students cannot learn on their own. Furthermore, students need additional attention and time to review and learn new material. CIA is the ideal platform, when coupled with 
traditional lecture, in which students have easy access to videos, instant feedback, additional time as needed and material is broken down in small units of instructions (Villarreal, 2003).

Liao (2007) performed a meta-analysis of 52 studies of 5000 students from first grade through college in different subject areas including mathematics and found that computer assisted instruction had moderate positive results on students' achievement when compared to traditional instruction alone. The mean effect size for mathematics was 0.291 . According to Slavin (as cited in Kulik, 2002) effect sizes above 0.25 are large enough to be "educationally significant".

Kodippili and Senaratne, (2008), conducted a study to determine if online homework using MyMathLab would help improved academic performance compared to traditional paper-based, instructor-graded homework, for 72 college algebra students. Kodippili and Senaratne selected two faculty members to teach two classes each. Each instructor taught one control group (traditional paper-based, instructor-graded homework) and one experimental group (online homework using MyMathLab). Based on the results, it was determined that there was no evidence to conclude that students' achievement was significantly better in the experimental group (34 students) than in the control group (38 students). However, student success rate (as measured by a percentages of A, B or C grades) was significantly higher among the experimental group (70\%), compared to the control group (49\%). The authors concluded that in addition to higher success rate, students also benefited from MML because it provided instant feedback on homework exercises and it allowed them to work on their own pace. 
Burch and Kuo (2010) investigated the efficacy of homework assignments completed using MyMathLab versus traditional paper homework assignment in improving final exam performance and retention rate among college algebra students at a university. There were 31 students in the experimental group (online homework using MML) and 21 students in the control group (traditional paper homework). There was no evidence that the mean score of the final exam in the experimental group was higher than the mean of the final exam scores in the control group. However, the retention rate in the experimental group was $86 \%$, while the retention rate for the control group was $58 \%$. (My study analyzed the efficacy of mastery learning delivered through MyMathLab. More details about it can be found in chapter 3).

Sowell (2011) carried out a study designed to measure the efficacy of mastery learning using MyMathLab versus traditional instruction on developmental mathematics at a college. The report of the study is quite weak, but it is included here since it is the only empirical study of the efficacy of aspects of mastery learning using MyMathLab located in the literature. Classes for the experimental group (340 students) were conducted in the "math emporium" and online. The math emporium is a place where student had access to computers and one on one tutoring. Students in the experimental group did not have access to traditional instruction and had to do all course work through MyMathLab. This course work included homework assignments, 10 quizzes, and five tests including a comprehensive final. Students in the experimental group were required to score at least $75 \%$ on each of five competencies, (a) Real number sense and operations, (b) Operations with algebraic expressions, (c) Solving linear equations, (d) Analyzing 
graphs, equations of lines, introduction to polynomials, and (e) Modeling and critical thinking, before being allowed to move to the next one. The mean final score for the experimental group was $10 \%$ higher than for the control group. The pass rate for the experimental group was $14 \%$ higher than the in the control group. However, it was not reported whether these represented statistically significant differences. It was reported that only $48.8 \%$ (166) of students in the experimental group were able to complete the first three competencies. Completion of the first three competencies was enough to complete a three-hour course with a passing grade. Only 34\% (117) completed all five competencies. There was no information reported on the number of students in the control group.

It was not clear whether or not any other studies on CAI were conducted to foster mastery learning. However, most CAI software provides the tools to carry out mastery learning if this is desired. These tools are videos, instant feedback, notes, access to a large data base of practice problems, easy accessibility from any computer with Internet access and, infinite patience and on line tutoring. Research seems to indicate that these features offer the ideal setting to improve passing rates among developmental and non-traditional students. Based on this, the current study used computer assisted instruction as a teaching strategy to deliver mastery learning via MyMathLab, in order to teach developmental mathematics to underprepared college students.

\section{Adult Learning Theories}

Malcolm Knowles was involved in higher education beginning in 1935, but it was only in 1968 that he first introduced the term "andragogy" in the adult education 
literature in United States; a term that was already being used in Europe (Tough, 1985). Knowles (1974) introduced the term andragogy to create awareness among U.S. educators of the differences between adult learning theory and the long-established concepts of pedagogy. Knowles (1984) posited four characteristics about adult learners: (a) they are self-directed and take responsibility for their own actions, (b) they have extensive depth of experience and they are ready to learn, (c) they are likely to engage in the learning process, and (d) they are goal oriented and task motivated. Kenner (2011) recently added that adult learners might expect a closer working-relationship between faculty member and student than non-adult learners.

It is important for institutions of higher learning to know their student populations in order to better address their needs since adult learners and child learners have different learning styles (Knowles, 1984). According to Kenner (2011), adult learners entering colleges and universities are members of three groups: (a) Students who have lost their jobs during the recession of 2008 and who need developmental classes before placing into college ready courses, (b) veterans returning from Iraq and Afghanistan, and the historically more typical (c) adults who have completed their high school degrees and who are now attending colleges and universities. Computer assisted instruction, like MyMathLab, is increasingly being implemented in colleges to ease the transition from the workforce to college for these groups of adult learners. Computer assisted instruction allows self-paced learning and provides on line tutoring, practice exams, instant feedback and videos to supplement traditional lecture course delivery. 
Faculty of colleges and universities must understand the difference between traditional students and adult learners. According to Horn (1996, as cited by Kenner, 2001), adult learners have three non-traditional characteristics: (a) They hold full time jobs, (b) They have dependents, and (c) They are financially independent. Frey (2007) identified four barriers for working adult students: (a) lack of time, (b) scheduling and location of courses, (c) the cost of education, and (e) family responsibilities. All of these may the reasons why more adult learners do not graduate on time or at all compared to traditional students. New teaching and learning strategies must be explored to address their needs. Through the use of computers, CAI allows non-traditional students the flexibility to learn from home, learn new content or review old material as needed by repetition and instant feedback, self pace, and have easy access from any computer with Internet access. These are features not found in traditional classroom teaching (Cotton, 1990; Estrine, 1975).

One of the challenges facing adult learners is high drop-out rate. One major reason as to why the high attrition rate among adult learners exists is that adult learners do not integrate well in higher education (Kenner, 2011). According to Tinto (1987), many college students drop out because they do not adjust well to college life, lack well defined goals, are uncertain about career paths, and are unwilling to make academic commitments. It is the responsibility of educators to be knowledgeable and aware of the different teaching and learning styles that would best benefit adult learners as they integrate to college life. Kenner (2001), recommends three learning strategies to better teach adult learners: Awareness, framing and competition and repetition. 
- Awareness: According to Kenner, being aware that adult learners have "gaps" on some of their basic knowledge which makes learning new material very challenging for them. Furthermore, adult learners may bring real life experience but they feel overwhelmed by the amount of new material needed to be learned on a weekly basis.

- Framing: It is important for educators to introduce effective learning strategies, including the right technology and books, to motivate adult learners to stay and be successful in college. An important aspect of effective teaching and learning is to identify which of the available strategies are effective and which are not (Kenner, 2011). One effective strategy when teaching adult learners, is to deliver new material in small units at a time to allow mastery learning (Abadir, 1993). Computer assisted instruction (CAI) can be set up to deliver new material in small units so that adult learners are not too overwhelmed (Li \& Edmonds, 2005).

- Competition and Repetition: Adult learners come into the classroom with metacognitive strategies already ingrained which may interfere with new learning strategies designed to help them succeed in college (Kenner, 2011). Kenner has recommended that educators develop learning strategies that would not compete with already established strategies through repetition. CAI facilitates the learning of new material through repetition and by removing the fear of failure or judgment (Estrine, 1975). 
Murk (1994) introduced five "Tested Techniques for Teaching Adults" and these are: (a) allow enough time for students to learn the material, (b) create a non-threatening learning environment, (c) get to know your adult learners, (d) allow time to practice new material, and (e) use multi-sensory for learning and remembering material. MyMathLab (MML) addresses four out of these five strategies. MML can be set up to allow students extra time to learn and practice on new material. Students may go back and review topics that they should have learned in prior mathematic courses. MML creates a nonthreatening learning environment where students can do their homework from home. When a student makes a mistake, instant feedback is provided. Through this feedback, the student can go through every step of the problem and a similar problem is generated to allow the student a chance to further practice the topic at hand. MML uses

multisensory tools such videos, flow charts, pictures, graphs and slides. All of these learning and teaching strategies transform the traditional classroom, where students learn by listening and observing the professor, to one-on-one tutoring or personalized teaching and learning environment (Bloom, 1984).

\section{Summary}

In Chapter 2, I examined the relevant literature with respect to the efficacy of mastery learning in the classroom and computer assisted instruction. Empirical findings on mastery learning were discussed and although many studies showed positive outcome, others did not. Empirical evidences shows that computer assisted instruction is most effective when it is used as a supplement to traditional instruction mode. In addition, computer assisted instruction is a good tool to use when teaching using mastery learning 
since it allows self-paced learning, instant feedback, videos, on line tutoring and easy access from any computer with Internet access.

The theoretical framework underpinning computer assisted instruction included Carroll's five key variables for school learning. Three out of these five variables are dependent on time, suggesting that instructional strategies that allowed learners to control learning time are more efficacious than those that did not. Based on Carroll's model of learning, two methods were examined. The first was Bloom's learning for mastery, which breaks teaching into small unit of instruction with frequent formative testing, comprehensible instruction and adequate time. The second was Keller's personalized system of instruction which is primarily based on students moving through lessons at their own pace.

Finally, adult learning theories were examined. The need to identify who the adult learners are and to offer them different learning experiences was established. Computer assisted instruction was identified as one of the strategies that can be used to provide individualized instruction.

Based on the theoretical and empirical findings noted in this summary, mastery learning coupled with MyMathLab was put forth as an instructional strategy and learning tool since it seems to meet the needs of adult learners better than the traditional instruction commonly used in many institutions, including the setting of this study. Using MML students can learn at their own paces, attempting to meet an objective or set of objectives until they are successful (i.e., mastery learning) through visual and audio modes using computer assisted instruction. It was suggested that MyMathLab should be a 
highly appropriate platform for teaching content to adults since it allows students to learn at their own paces, to have access to instant feedback, infinite patience, quizzes and to be able to use diverse modes of learning. 


\section{CHAPTER III}

\section{METHODOLOGY}

The purpose of this study was to determine the efficacy of mastery learning in a developmental mathematics course using a particular computerized mathematics package MyMathLab (MML). The investigation used a quasi-experimental design to test the seven hypotheses. This chapter presents a description of the population, procedure and data analysis.

\section{Hypotheses}

This study examined the efficacy of mastery learning supplemented by computer assisted instruction using MyMathLab on student overall performance in developmental mathematics. The independent variable was the method of instruction of the participants (traditional instruction coupled with MML set up for mastery learning, traditional instruction coupled with MML but with no provision for mastery learning, and traditional instruction without MML or mastery learning), and the dependent variables were the students' final exam scores and the passing status in MAT1033 (Intermediate Algebra). The level of significance was set at $\alpha<0.05$. The following were the hypotheses of the study:

$\mathrm{H}_{\mathrm{a} 1}$ : Students who were taught using mastery learning coupled with MML in MAT1033 will have a higher mean final examination score, when adjusted by the pretest score, than those students who were not taught using mastery learning supplemented by MML (groups A and B). 
$\mathrm{H}_{\mathrm{a} 2}$ : Students who were taught using mastery learning coupled with MML in MAT1033 will have a higher mean final examination score, when adjusted by the pretest score, than those students who were not taught using mastery learning nor supplemented by MML (groups A and C).

$\mathrm{H}_{\mathrm{a} 3}$ : Students who were taught using MyMathLab in the absence of mastery learning in MAT1033 will have a higher mean final examination score, when adjusted by the pretest score, than those students who were not taught using mastery learning and were not supplemented by MML (groups B and C).

$\mathrm{H}_{\mathrm{a} 4}$ : The proportion of students who were taught using mastery learning coupled with MML who received a passing grade in MAT1033 will be significantly higher than the proportion of passing students who were not taught using mastery learning but were supplemented by MML who received a passing grade in MAT1033 (groups A and B).

$\mathrm{H}_{\mathrm{a} 5}$ : The proportion of students who were taught using mastery learning coupled with MML who received a passing grade in MAT1033 will be significantly higher than the proportion of passing students who were not taught using mastery learning and were not supplemented by MML who received a passing grade in MAT1033 (groups A and C).

$\mathrm{H}_{\mathrm{a} 6}$ : The proportion of students who were not taught using mastery learning but were supplemented with MML who received a passing grade in MAT1033 will be significantly higher than the proportion of passing students who were not taught 
using mastery learning and were not supplemented by MML who received a passing grade in MAT1033 (groups B and C).

$\mathrm{H}_{\mathrm{a} 7}$ : There is a significant difference between the adjusted means of final examination scores, adjusted for pretest scores and time on task, of at least one pair of treatment groups.

\section{General Research Methodology}

I conducted a quantitative study using a pretest/posttest, non-equivalent groups quasi-experiment design (NEGD) with one independent variable that is whether or not the students were taught using mastery learning supplemented by MyMathLab. Quasiexperimental design was used because it was not possible to randomly assign participants to groups. Mathematics achievement was measured using a common final examination score. A common pretest scores was used as a covariate. The pretest was administered during the first week of classes.

The NEGD is appropriate when analyzing groups that are similar or comparable as the treatment and control groups. Furthermore, the NEGD works similarly to the pretest and post-test randomized experiment but it does not require random assignment (Trochim, 2006). Therefore, it is more vulnerable to certain Type I errors. Efforts were made to select groups that have as many similarities as possible to make a fair comparison between the control and experimental group. When dealing with nonequivalent groups, one may encounter pre-existing differences between groups which may affect the results and interpretation of the study, causing a Type I error. I addressed 
this issue by using the reliability-corrected analysis of covariance (ANCOVA), which adjusts the pretest for measurement error. ANCOVA assumes homogeneity of variance and homogeneity of regression slopes (Trochim, 2006). I tested these assumptions, details are provided in Chapter 4.

\section{Participants}

The participants taking part in this study were students enrolled in MAT1033 at the Homestead Campus, one of Miami Dade College's eight campuses in Miami Dade County, Florida. The Homestead Campus is located in the city of Homestead approximately 36 miles south of Miami. Upon registration at Miami Dade College, all students are required to take the Computerized Placement Test (CPT) to assess their levels of mathematics proficiency. Students are placed in the appropriate mathematics course based on their CPT scores. MAT1033 is the most advanced developmental mathematics course required for underprepared students. Those students who receive a passing grade are allowed to enroll in College Algebra (MAC1105) or Mathematics for Liberal Arts Majors (MGF1106).

There are three possible ways students may be placed in MAT1033: (a) based on students' CPT scores, (b) by successfully completing MAT0022C (a lower level college preparatory course that covers basic arithmetic and basic algebra), and (c) by successfully completing MAT0028 (a college preparatory course that covers basic algebra). This placement method is intended to have students begin at the same mathematics proficiency level as they enter MAT1033, creating similar or comparable classes. 
During the fall of 2013, at the Homestead campus the student population was about $64 \%$ Hispanic, $19 \%$ Black, $12 \%$ White, and $2.3 \%$ other; $61.6 \%$ women and $38.4 \%$ men (Pousa, 2014). The student sample who participated in this study were $58 \%$ female, $42 \%$ male and everyone was 18 years of age or older. I conducted this study during the Fall term of 2013.

\section{Procedure}

In this study, there were seven similar MAT1033 classes of approximately 30 developmental mathematics students for a total of around 210 participants. Three full time faculty members volunteered to work with me in this research. They selected their classes based on seniority. Two of the three instructors selected at least two MAT1033 classes and the third instructor selected three classes of MAT1033. All seven classes met during the day, Monday through Friday. I made sure that all three instructors understood the significance and procedures of this study by going over the first three chapters of this study with them. All three instructors had previously used MML to assign homework and quizzes and to monitor students' progress.

Students in this study were taught using one of three different methods of instruction. The first group (group A) used MML as a supplement to traditional instruction using mastery learning. The second group (group B) used MML as a supplement to traditional instruction without the use of mastery learning, and the last group (group C) was taught through traditional instruction only. Two instructors taught MAT1033 using the first and second methods while the third instructor taught three sections of MAT1033 using each of the three methods of instructions. The three groups 
were compared using students' final course grades and the passing status (pass, fail or withdraw). In order to maintain students' privacy, I used the last four digits of their student school identification number to identify them.

All three instructors randomly assigned their classes to treatments groups. All seven classes were taught via traditional instruction. Students in groups A and B also received the appropriate training on how to use MyMathLab during the first week of classes. They had access to MyMathLab at all times from any computer with Internet access. Students in groups A and B were able to use MML to do their homework, watch videos, and receive instant feedback and access to the e-book. However, only students in group A had access to practice exams through MML (pre-tests and post-tests). Instructors using mastery learning coupled with computer assisted instruction were able monitor students' performance based on pre-test and post-tests through MyMathLab. Based on this information, instructors assigned specific homework exercises to students who needed extra reinforcement on particular topics until these students achieve at least $70 \%$ on these topics (mastery learning).

The students in group $\mathrm{C}$ had no access to MyMathLab. They did their homework exercises from the book assigned for MAT1033 and not through MyMathLab. All three groups had access to tutoring services provided to all students at the Homestead Campus and any of the other seven campuses throughout Miami Dade County. Tutoring services are provided to students on a one-on-one basis or in groups of up to five students. In addition, all three groups also had access to the instructors' office hours. Table 1 summarizes the treatments that were received by the participants in each of the groups. 
Table 1

Characteristics of the Three Groups

\begin{tabular}{|c|c|c|c|}
\hline Treatment & Group A & Group B & Group C \\
\hline $\begin{array}{l}\text { Traditional instruction } \\
\text { and access to tutoring } \\
\text { labs }\end{array}$ & Yes & Yes & Yes \\
\hline MyMathLab (MML) & Yes & Yes & No \\
\hline $\begin{array}{l}\text { MML videos, instant } \\
\text { feedback on } \\
\text { homework, e-book and } \\
\text { chat-rooms }\end{array}$ & Yes & Yes & No \\
\hline $\begin{array}{l}\text { MML pretest/posttest, } \\
\text { monitoring students' } \\
\text { progress (personalized } \\
\text { instruction through } \\
\text { MML). Instructors } \\
\text { recommend plan of } \\
\text { action depending on } \\
\text { students' process and } \\
\text { needs until students } \\
\text { achieve mastery of the } \\
\text { topic (set at } 70 \% \text { ) }\end{array}$ & Yes & No & No \\
\hline
\end{tabular}

Historically at the Homestead Campus, MAT1033 has a high attrition rate of about $29 \%$, which means there might be about 149 students still enrolled by the end of the term. In the present study 173 students took the final examination. This allowed for a power equal or greater than 0.80 for detecting a minimum effect size of $f=0.25$ at the $\alpha=$ 0.05 level of significance.

\section{Instrumentation}

Three measures were used in this study. The first two measures were students' scores on the common pretest given at the beginning of the term and a comprehensive common final examination score obtained at the end of the semester. The common pretest 
and final exams were created by all three instructors using a test-generator that accompanied the instructor's book. The third measure was on the proportion of students with passing class grades in MAT1033 at the end of the semester.

\section{Data Collection and Analysis}

The data collection method consisted of administering and gathering final examination scores (posttest), pretests and final course grades for the students using mastery learning coupled with MML, students not using MML in the absence of mastery learning and students not using mastery learning or MML, in seven groups enrolled in MAT1033 taught by all three instructors. All students took a common pretest and a common final exam.

Descriptive statistics were calculated for each of the variables. Hypotheses 1 through 3 were tested using a one-way analysis of covariance (ANCOVA) using participants' pre-test mathematics scores as the covariate, the treatment as the independent variable, and the MAT1033 final examination as the dependent variable. Hypotheses 4 through 6 were tested using a chi-square test. All statistical tests were done at the $\alpha=.05$ level of significance. The seventh hypothesis was testing using a one-way ANCOVA utilizing the pretest scores and time on task as the covariate, treatment as the independent variable, and the final examinations as the dependent variable. 


\section{CHAPTER IV}

\section{RESULTS}

The results of the study are presented in this chapter. I investigated whether there were any significant differences in mathematics performance as measured by students' final exam scores (posttest scores in this study), and passing status among students in three different treatment groups. Students in group A were taught using mastery learning supplemented by MyMathLab and traditional instruction, students in group B were taught by traditional instruction supplemented by MyMathLab in the absence of mastery learning, and students in group $\mathrm{C}$ were taught by traditional instruction in the absence of mastery learning and MyMathLab. The independent variable was the method of instruction and the dependent variables were students' final exam scores and passing status. Pretreatment mathematics test scores and, later, time on task measures were used as covariates. This chapter contains the analysis of seven hypotheses concerning the effectiveness of mastery learning supplemented by MyMathLab on the achievement of developmental mathematics students enrolled in MAT1033.

\section{Data Analysis}

\section{Covarying Only Pretest Scores}

A one-way analysis of covariance was conducted using the pretest score as the covariate, type of treatment as the independent variable and posttest score as the dependent variable. Descriptive statistics of the covariate are presented in Table 2. 
Table 2

Pretest Descriptive Statistics

\begin{tabular}{lccc}
\hline Groups & $M$ & $S D$ & $n$ \\
\hline A & 72.13 & 20.593 & 78 \\
B & 67.42 & 22.065 & 74 \\
C & 66.29 & 17.641 & 21 \\
Total & 69.40 & 20.951 & 173 \\
\hline
\end{tabular}

\section{Omnibus Analysis of Covariance}

Before a one-way ANCOVA, with level of significance set at $\alpha=0.05$, was conducted to analyze the first three null hypotheses, an analysis of variance was done to test the homogeneity of slopes assumption. This analysis indicated that the there was no significant interaction between the covariate (pretest) and the dependent variable (posttest), which indicates that the data met the homogeneity of slopes assumption, $F(2,167)=.219, p=.804$, partial $\eta^{2}=.003$. With this assumption satisfied, a one-way ANCOVA was conducted. The results of this analysis indicated that there was a significance difference among the three groups, $F(2,169)=3.463, p=.034$, partial $\eta^{2}=$ .039. About $4 \%$ of the variance of the dependent variable (posttest) was due to the independent variable (treatment). Table 3 provides a summary of the ANCOVA. 
Table 3

ANCOVA Summary

\begin{tabular}{lrrrr}
\hline Source & $d f$ & $M S$ & $F$ & $p$ \\
\hline Pretest & 1 & 20844.796 & 231.417 & .001 \\
Group & 2 & 311.899 & 3.463 & .034 \\
Error & 169 & 90.075 & & \\
Total & 173 & & & \\
Corrected Total & 172 & & & \\
\hline
\end{tabular}

The means for the sample on the posttest, adjusted for the covariate were as expected for the three groups. Group A had the highest adjusted mean $(M=77.751)$, group B had a lower adjusted mean $(M=76.146)$ and group $\mathrm{C}$ had the lowest adjusted mean $(M=71.603)$. Table 4 provides the adjusted and unadjusted posttest means for the three groups.

Table 4 Final Examination Posttreatment Scores Adjusted by Pretreatment Scores

\begin{tabular}{ccccccc}
\hline & \multicolumn{2}{c}{ Unadjusted } & & \multicolumn{2}{c}{ Adjusted } & \\
\cline { 2 - 3 } \cline { 5 - 6 } Groups & $M$ & $S D$ & & $M$ & $95 \%$ IC & $n$ \\
\hline A & 79.19 & 14.048 & & 77.751 & {$[75.62,79.88]$} & 78 \\
B & 75.09 & 15.418 & & 76.146 & {$[73.96,78.33]$} & 74 \\
C & 69.95 & 13.265 & & 71.603 & {$[67.51,75.70]$} & 21 \\
Total & 76.32 & 14.800 & & & & 173 \\
\hline
\end{tabular}

\section{Tests of Hypotheses Concerning Group Means}

Tests for pairwise differences among the means of the three groups were conducted with Bonferroni adjustments for multiple comparisons. The null hypothesis $\left(\mathrm{H}_{01}\right)$ that there was no significant difference between the adjusted means of final examination scores of students in MAT1033 who were taught using mastery learning 
techniques (ML) supplemented by MyMathLab (MML) and those who were taught using MML with no ML component $\left(\mu_{\mathrm{A}}=\mu_{\mathrm{B}}\right)$ was tested against the alternative hypothesis $\left(\mathrm{H}_{\mathrm{a} 1}\right)$ that students who were taught using mastery learning coupled with MML in MAT1033 had higher mean final examination scores than students who were taught using MML without mastery learning $\left(\mu_{\mathrm{A}}>\mu_{\mathrm{B}}\right)$. The null $\mathrm{H}_{01}$ was not rejected, $p=.904$.

The null hypothesis $\left(\mathrm{H}_{02}\right)$ that there was no significant difference between the adjusted means for final examination scores of students in MAT1033 who were taught using ML supplemented by MML and those students who were taught without MML and no mastery learning $\left(\mu_{\mathrm{A}}=\mu_{\mathrm{C}}\right)$ was tested against the alternative hypothesis $\left(\mathrm{H}_{\mathrm{a} 2}\right)$ that students who were taught using ML coupled with MML had higher final examination scores than those students who were taught without MML and no MLT $\left(\mu_{\mathrm{A}}>\mu_{\mathrm{C}}\right)$. The null hypothesis $\left(\mathrm{H}_{02}\right)$ was rejected, $p=.028$.

The null hypothesis $\left(\mathrm{H}_{03}\right)$ that there was no significant difference between the adjusted means for final examination scores of students in MAT1033 who were taught using MML in the absence of mastery learning and those students who were taught without MML and no ML $\left(\mu_{\mathrm{B}}=\mu_{\mathrm{C}}\right)$ was tested against the alternative hypothesis $\left(\mathrm{H}_{\mathrm{a} 3}\right)$ that students who were taught using MML but no ML had higher final examination scores than those students who were taught without MML and no ML $\left(\mu_{B}>\mu_{C}\right)$. The null hypothesis $\left(\mathrm{H}_{03}\right)$ was not rejected, $p=.164$. 


\section{Tests of Hypotheses Concerning Frequencies of Passing Status}

Chi-square tests for association were conducted to determine whether passing status was significantly different among students in group A, group B or group C. The two variables were the method of instruction and the passing status with the three levels (passed, failed and withdrew). Method of instruction and passing status were found to be significantly related, Pearson $\chi^{2}(4, N=210)=13.029, p=.01$, Cramer's V $=0.176$. Table 5 provides the passing status for all three groups. Each superscript letter denotes a subset of Groups categories whose column proportions do not differ significantly from each other at the .05 level.

Table 5

Passing Status by Groups

\begin{tabular}{ccccc}
\hline & \multicolumn{3}{c}{ Groups } & Total \\
\cline { 2 - 4 } Passing Status & $\mathrm{A}$ & $\mathrm{B}$ & $\mathrm{C}$ & \\
\hline Passed & $77.8 \% \%^{\mathrm{a}}$ & $64.4 \% \mathrm{o}^{\mathrm{a}, \mathrm{b}}$ & $43.3 \%^{\mathrm{b}}$ & $67.2 \%$ \\
Failed & $8.9 \%^{\mathrm{a}}$ & $17.8 \%{ }^{\mathrm{a}}{ }^{\mathrm{a}} \mathrm{b}$ & $26.7 \% \mathrm{o}^{\mathrm{b}}$ & $15.2 \%$ \\
Withdrew & $13.3 \%{ }^{\mathrm{a}}$ & $17.8 \%{ }^{\mathrm{a}}$ & & \\
& & & $30.0 \%{ }^{\mathrm{a}}$ & $17.6 \%$ \\
\hline
\end{tabular}

Note: In this table the percentages of students who passed, failed or withdrew in each group is provided.

More tests were conducted to evaluate pairwise difference on passing status among the three groups. The last three hypotheses were tested using a Chi-Square $\left(\chi^{2}\right)$; the level of significance was set at $\alpha=0.05$. The null hypothesis $\left(\mathrm{H}_{04}\right)$ that there was no significant difference in the proportion of students who passed MAT1033 who were taught using mastery learning coupled with MML and those students who were taught with MML but with no mastery learning was tested against the alternative hypothesis $\left(\mathrm{H}_{\mathrm{a} 4}\right)$ that the proportion of students who were taught using mastery learning coupled with MML who received a passing grade in MAT1033 was significantly higher than the 
proportion of students who were taught without mastery learning but were supplemented by MML who received a passing grade in MAT1033. The comparison analysis between group A and group B did not find any statistically significant difference for the method of instruction and passing status on two levels (failed and withdrew), Pearson $\chi^{2}(2, N=180)$ $=4.363, p=0.113$, Cramer's $\mathrm{V}=0.156$; however there was a significant difference on the passing grade. The hypothesis $\left(\mathrm{H}_{04}\right)$ was rejected. Table 6 provides a summary of the passing status for groups A and B. Each superscript letter denotes a subset of Groups categories whose column proportions do not differ significantly from each other at the .05 level.

Table 6

Passing Status by Groups A and B

\begin{tabular}{|c|c|c|c|}
\hline \multirow[b]{2}{*}{ Passing Status } & \multicolumn{2}{|c|}{ Groups } & \multirow[t]{2}{*}{ Total } \\
\hline & A & B & \\
\hline Passed & $77.8 \%{ }^{\mathrm{a}}$ & $64.4 \%{ }^{b}$ & $71.1 \%$ \\
\hline Failed & $8.9 \%{ }^{\mathrm{a}}$ & $17.8 \%{ }^{\mathrm{a}}$ & $13.3 \%$ \\
\hline Withdrew & $13.3 \%^{\mathrm{a}}$ & $17.8 \%{ }^{\mathrm{a}}$ & $16.6 \%$ \\
\hline
\end{tabular}

The null hypothesis $\left(\mathrm{H}_{05}\right)$ that there was no significant difference in the proportion of students who passed MAT1033 who were taught using mastery learning coupled with MML and those students who were taught without mastery learning and no MML was tested against the alternative hypothesis $\left(\mathrm{H}_{\mathrm{a}}\right)$ that the proportion of students who were taught using mastery learning coupled with MML who received a passing grade in MAT1033 will be significantly higher than the proportion of students who were not taught using mastery learning and were not supplemented by MML who received a passing grade in MAT1033.The comparison analysis between group A and group C yielded a statistically significant difference for the method of instruction and passing 
status on all three levels (passed, failed and withdraw), Pearson $\chi(2, N=120)=12.724, p$ $=0.002$, Cramer's $\mathrm{V}=0.326$. The null hypothesis $\left(\mathrm{H}_{05}\right)$ was rejected. Table 7 provides a summary of the passing status between groups A and C. Each superscript letter denotes a subset of Groups categories whose column proportions do not differ significantly from each other at the .05 level.

Table 7

Passing Status by Groups A and C

\begin{tabular}{|c|c|c|c|}
\hline \multirow[b]{2}{*}{ Passing Status } & \multicolumn{2}{|c|}{ Groups } & \multirow[t]{2}{*}{ Total } \\
\hline & A & $\mathrm{C}$ & \\
\hline Passed & $77.8 \%{ }^{\mathrm{a}}$ & $43.3 \%{ }^{b}$ & $69.2 \%$ \\
\hline Failed & $8.9 \% \%^{\mathrm{a}}$ & $26.7 \%$ b & $13.3 \%$ \\
\hline Withdrew & $13.3 \% \%^{\mathrm{a}}$ & $30.0 \%{ }^{b}$ & $17.5 \%$ \\
\hline
\end{tabular}

The null hypothesis $\left(\mathrm{H}_{06}\right)$ that there was no significant difference in the proportion of students who passed MAT1033 who were taught using MML in the absence of mastery learning and those students who were taught without mastery learning and no MML was tested against the alternative hypothesis $\left(\mathrm{H}_{\mathrm{a} 6}\right)$ that the proportion of students who were not taught using mastery learning but were supplemented with MML who received a passing grade in MAT1033 will be significantly higher than the proportion of students who were not taught using mastery learning and were not supplemented by MML who received a passing grade in MAT1033.The comparison analysis between group B and group C did not find any statistically significant difference for the method of instruction and passing status on two levels (failed and withdraw), Pearson $\chi^{2}(2, N=120)$ $=4.197, p=0.123$, Cramer's $\mathrm{V}=0.187$, but there was a significant difference on passing grade. The null hypothesis $\left(\mathrm{H}_{06}\right)$ was rejected. Table 8 provides a summary of the passing 
status for groups B and C. Each superscript letter denotes a subset of groups' categories whose column proportions do not differ significantly from each other at the .05 level.

Table 8

Passing Status by Groups B and C

\begin{tabular}{|c|c|c|c|}
\hline \multirow[b]{2}{*}{ Passing Status } & \multicolumn{2}{|c|}{ Groups } & \multirow[t]{2}{*}{ Total } \\
\hline & B & $\mathrm{C}$ & \\
\hline Passed & $64.0 \%{ }^{\mathrm{a}}$ & $43.3 \%{ }^{b}$ & $69.2 \%$ \\
\hline Failed & $17.8 \%{ }^{\mathrm{a}}$ & $26.7 \%{ }^{\mathrm{a}}$ & $13.3 \%$ \\
\hline Withdrew & $17.8 \%{ }^{\mathrm{a}}$ & $30.0 \% \%^{\mathrm{a}}$ & $17.5 \%$ \\
\hline
\end{tabular}

A two-sided contingency table analysis was also conducted to evaluate whether passing status was significantly different among all three instructors who participated in this study. The two variables were the instructors and the passing status with the three levels (passed, failed and withdraw). Instructors and passing status were not found to be significantly different on any of the three levels, Pearson $\chi^{2}(4, N=210)=2.690, p=$ 0.611 , Cramer's $\mathrm{V}=0.080$. Table 9 provides the proportions of the passing status from each instructor.

Table 9

Passing Status by Instructor

\begin{tabular}{lccc}
\hline Instructor & Passed & Failed & Withdrew \\
\hline 1 & $64.4 \%$ & $16.7 \%$ & $18.9 \%$ \\
2 & $75.0 \%$ & $10.0 \%$ & $15.0 \%$ \\
3 & $63.3 \%$ & $18.3 \%$ & $18.3 \%$ \\
\hline
\end{tabular}

A discriminant analysis was conducted to predict whether a student would pass or fail MAT1033 based on the predictor, time on task (time on task was defined as the time students spent in the tutoring laboratory or logged into MML). The discriminant function showed a significant relationship between passing status with two levels (passed and 
failed) and the predictor, accounting for $26.41 \%$ of variability between those who passed and those who failed. The classification results revealed that overall $89 \%$ were correctly classified. Table 10 shows that $98.6 \%$ of students who were predicted to pass the class based on the time students spent on task, passed and $46.9 \%$ of those student who were predicted to fail the class based on time they spent on task, failed. Table 11 shows the minutes means for all three groups. Table 12 shows the minutes means for students' passing status.

Table 10

Classification Results

\begin{tabular}{llccc}
\hline & & \multicolumn{2}{c}{ Predicted Group Membership } & \\
\cline { 3 - 4 } Source & Passing Status & Passed & Failed & Total \\
\hline Original Count & Passed & 139 & 2 & 141 \\
& Failed & 17 & 15 & 32 \\
\multirow{3}{*}{ Percent Count } & Passed & 98.6 & 1.4 & 100 \\
& Failed & 53.1 & 46.9 & 100 \\
\hline
\end{tabular}

Table 11

Time on Task by Group (minutes)

\begin{tabular}{ccrc}
\hline Groups & $M$ & \multicolumn{1}{c}{$S E$} & $95 \%$ IC \\
\hline A & 2481.571 & 99.157 & {$[2286.079,2677.063]$} \\
B & 2188.418 & 98.929 & {$[1993.375,2383.460]$} \\
C & 1532.095 & 171.231 & {$[1194.505,1869.685]$} \\
\hline
\end{tabular}

Table 12

Time on Task by Passing Status (minutes)

\begin{tabular}{lrrr}
\hline Passing status & \multicolumn{1}{c}{$M$} & \multicolumn{1}{c}{$S D$} & Total \\
\hline Passed & 2739.13 & 783.362 & 141 \\
Failed & 1556.39 & 714.923 & 32 \\
Withdrew & 817.30 & 269.856 & 37 \\
Total & 2220.29 & 1047.375 & 210 \\
\hline
\end{tabular}




\section{Covarying Both Pretest Score and Time on Task}

Considering the ability of the time on task variable to predict educational outcomes of students in this study, further investigation of this variable was carried out. The time on task, defined the time students spent in the tutoring laboratory and/or logged in to MyMathLab, was added as a second covariate to the ANCOVA. Descriptive statistics for the final examination scores adjusted for both the pretest scores and time on task are listed in Table 13.

Table 13

Final Examination Scores

\begin{tabular}{ccccccc}
\hline & \multicolumn{2}{c}{ Unadjusted } & & \multicolumn{2}{c}{ Adjusted } & \\
\cline { 2 - 3 } \cline { 5 - 6 } Groups & $M$ & $S D$ & & $M$ & $95 \%$ IC & $n$ \\
\hline A & 79.19 & 14.048 & & 76.69 & {$[74.71,78.69]$} & 78 \\
B & 75.09 & 15.418 & & 76.39 & {$[74.39,78.40]$} & 74 \\
C & 69.95 & 69.950 & & 74.65 & {$[70.74,78.56]$} & 21 \\
Total & 76.32 & 14.800 & & & & 173 \\
\hline
\end{tabular}

The null hypothesis $\left(\mathrm{H}_{07}\right)$ that there was no significant difference between the adjusted means of final examination scores, adjusted for pretest score and time on task, of students who were taught using each of the three treatments was tested against the alternative hypothesis $\left(\mathrm{H}_{07}\right)$ that there was a significant difference between the adjusted means of at least one pair of treatment groups. The null hypothesis $\left(\mathrm{H}_{07}\right)$ was not rejected. Since there were no significant differences found between adjusted means of treatment groups, no post-hoc analysis was conducted. Table 14 is the source table for this ANCOVA. 
Table 14

Covarying Both Pretest Score and Time on Task

\begin{tabular}{lrrrrr}
\hline Source & $d f$ & $M S$ & $F$ & $p$ & $\eta^{2}$ \\
\hline Pretest & 1 & 18008.108 & 236.841 & .001 & .585 \\
Time on Task & 1 & 2448.814 & 32.207 & .001 & .161 \\
Group & 2 & 31.435 & .413 & .662 & .005 \\
Error & 168 & 76.034 & & & \\
Total & 173 & & & & \\
Corrected Total & 172 & & & & \\
\hline
\end{tabular}

A discriminant analysis was conducted to predict whether a student would pass or fail MAT1033 based on the added predictor pretest score. The discriminant function using both pretest scores and time on task as predictors showed a significant relationship between passing status with two levels (passed and failed) and the predictors, accounting for $58.3 \%$ of variability between those who passed and those who failed. The classification results revealed that overall $94 \%$ were correctly classified. Table 13 shows that $98.6 \%$ of students who were predicted to pass the class based on the time students spent on task, passed and $71.9 \%$ of those student who were predicted to fail the class based on time they spent on task, failed. Adding the pretest score as a predictor of passing status resulted in a change from $26 \%$ to $58.3 \%$ of the variability between those who passed or failed. It increased overall accuracy of the prediction from $89 \%$ correct to $94 \%$ correct. The proportion of participants correctly predicted to pass the course did not change, but the proportion correctly predicted to fail increased from $47 \%$ to $72 \%$. 
Table 15

Classification Results using Pretest and Time on Task as Predictors $(N=173)$

\begin{tabular}{lllcc}
\hline & & \multicolumn{2}{c}{ Predicted Group Membership } & \\
\cline { 3 - 4 } Source & Passing Status & Passed & Failed & Total \\
\hline Original Count & Passed & 139 & 2 & 141 \\
& Failed & 9 & 23 & 32 \\
Original Percent & Passed & 98.6 & 1.4 & 100 \\
& Failed & 28.1 & 71.9 & 100 \\
\hline
\end{tabular}

\section{Summary}

A one-way ANCOVA, with level of significance set at $\alpha=0.05$, was conducted to analyze the first three hypotheses of this study. The results of the ANCOVA revealed that there were significant differences among the three groups when posttreatment scores were adjusted for pretreatment scores. Based on this result, tests for pairwise differences among the means of the three groups were conducted with Bonferroni adjustments for multiple comparisons. The first null hypothesis $\left(\mathrm{H}_{01}\right)$ was not rejected because the analysis revealed no significant difference between the adjusted final mean scores of groups A and B. There was a significant difference between the adjusted final mean scores of groups $\mathrm{A}$ and $\mathrm{C}$, hence the second null hypothesis $\left(\mathrm{H}_{02}\right)$ was rejected. Finally, there was no significant difference between the adjusted final mean scores of groups B and $\mathrm{C}$. Therefore, the third null hypothesis $\left(\mathrm{H}_{03}\right)$ was not rejected.

Chi-square tests, with significance levels set at $\alpha=0.05$, revealed that there was a significant difference in the passing status with three levels (pass, fail and withdraw) and the method of instruction among the three groups hence more tests were conducted to 
evaluate the pairwise difference among groups. Even though the pairwise test between group A and B did not reveal any significant difference in the proportion of students who failed or withdrew the class, there was a significant difference in passing grade, hence the null hypothesis $\left(\mathrm{H}_{04}\right)$ was rejected. The pairwise test between group $\mathrm{A}$ and $\mathrm{C}$ revealed a significant difference in passing status on all three levels; hence the null hypothesis $\left(\mathrm{H}_{05}\right)$ was rejected. Finally, the pairwise test between group B and C revealed no significant difference on the proportion of students who failed or withdrew the class, but there was a significant difference on the proportion of students who passed, hence the null hypothesis $\left(\mathrm{H}_{06}\right)$ was rejected as well.

In addition, a chi-square test from a two-sided contingency table analysis revealed that there was no significant difference in the distribution of passing final course grades among all three instructors who participated in this study. Finally, the classification results from a discriminant function analysis revealed that overall $89 \%$ of students were correctly classified based as passing or failing based on a measure of time on task.

Considering the predictability of time on task for course passing rate, the ANCOVA described above was repeated adding time on task as a second covariate. This resulted in a finding of no significant differences in the adjusted final examination mean scores between the three treatment groups. Because of this, no group comparisons were done using this model. However, it was found that the addition of pretest score as a predictor in the discriminant function analysis increased the probability of an accurate prediction of passing status. 


\section{CHAPTER V}

\section{DISCUSION AND RECOMMENDATIONS}

The purpose of this study was to analyze the effectiveness of mastery learning on the achievement of students enrolled in MAT1033, a developmental mathematics course, using a type of computer assisted instructions known as MyMathLab (MML; Pearson, 2013), at a 4-year college. The study was conducted with seven sections of MAT1033 taught by three full time faculty at Miami-Dade College with two instructors teaching two sections each and one teaching three. In each of the seven sections instructors taught the course using one of the three instructional strategies: (a) mastery learning supplemented by MML along with traditional instruction, (b) MML in the absence of mastery learning techniques along with traditional instruction, and (c) traditional instruction only. Two hundred ten students took the pretest during the first week of classes and 173 took the final exam. Data was gathered about scores on a pretest administered during the first week of the semester, a final examination score, and the students' passing status at the end of the semester. In addition a measure of time on task was obtained using the total time spent by students in the tutoring laboratory or logged in to MyMathLab.

\section{Overview of the Problem}

Decades of research have shown that many students enrolled in developmental courses do not do well in classes taught though traditional instruction because they do not have basic skills, such as note taking and listening stills, they need to succeed under this teaching modality (Boylan \& Saxon, 2002; Roueche \& Kirk, 1974). The need to find better ways to effectively teach developmental courses is dire since about $70 \%$ of 
students taking developmental mathematics courses do not succeed and only $20 \%$ of those taking developmental courses go on to complete one college level mathematic course (Bailey, 2008; Bailey \& Cho, 2010). In addition, the three post-secondary courses with the highest attrition rates are all in developmental mathematics. Hence, students enrolled in these courses are less likely to graduate from college (Barnett \& Fay, 2013; Cullinane \& Uri, 2010). Failing developmental mathematics courses not only prevents students from graduating from college but it also affects their chances of finding employment (Hodara, 2011). According to Rivera-Batiz (as cited in Hodar, 2011), young adults with low levels of basic quantitative skills, especially arithmetic skills, which are covered in developmental mathematics, are more likely to be unemployed.

Issues that students face when enrolled in developmental mathematics, as stated above, led me to ask the following research question: Will a particular teaching method using mastery learning and supplemented by computer assisted instruction increase levels of achievement and students' passing rate in developmental mathematics courses over and above teaching methods supplemented by computer assisted instruction where mastery learning is not used, and a teaching method that is based on lecture and recitation, and does not use MML as a supplement, at all?

The following were the null hypotheses of this study.

$\mathrm{H}_{01}$ : There is no significant difference between the adjusted means of final examination scores of students in MAT1033 who were taught using mastery learning techniques (MLT) supplemented by MyMathLab (MML) and those who were taught using MML with no MLT component. 
$\mathrm{H}_{02}$ : There is no significant difference between the adjusted means for final examination scores of students in MAT1033 who were taught using MLT supplemented by MML and those students who were taught without MML and no mastery learning.

$\mathrm{H}_{03}$ : There is no significant difference between the adjusted means for final examination scores of students in MAT1033 who were taught using MML in the absence of mastery learning and those students who were taught without MML and no ML.

$\mathrm{H}_{04}$ : There is no significant difference in the proportion of students who passed MAT1033 who were taught using mastery learning coupled with MML and those students who were taught with MML but with no mastery learning.

$\mathrm{H}_{05}$ : There is no significant difference in the proportion of students who passed MAT1033 who were taught using mastery learning coupled with MML and those students who were taught without mastery learning and no MML.

$\mathrm{H}_{06}$ : There is no significant difference in the proportion of students who passed MAT1033 who were taught using MML in the absence of mastery learning and those students who were taught without mastery learning and no MML.

$\mathrm{H}_{07}$ : There is no significant difference between the adjusted means of final examination scores, adjusted for pretest score and time on task, of students who were taught using each of the three treatments. 


\section{Results}

This study investigated the impact of mastery learning supplemented by computer assisted instruction on the achievement of students enrolled in a particular developmental mathematics course, MAT1033, using a computer software called MyMathLab.

Descriptive statistics and one-way analysis of covariance (ANCOVA) were performed on data related to null hypotheses 1,2,3, and 7. A chi-square test of association was performed to analyze the distribution of passing status (pass, fail and withdraw) between treatments (null hypotheses 4, 5, and 6).The following results were generated by the study.

Hypothesis 1. Because an ANCOVA revealed that there was a significant difference in the means of adjusted posttest final examinations for MAT1033 based on method of instruction, a pairwise analysis with a Bonforonni was done to test for any significant difference among the means of the three groups. It was found that there was no significant difference on the adjusted means of final examination scores of students who were taught using mastery learning coupled with MML and scores of students who were taught with MML in the absence of mastery learning (Group A vs. Group B). Therefore, the null hypothesis $\left(\mathrm{H}_{01}\right)$ was not rejected. This result showed no evidence that computer assisted instruction without mastery learning techniques was less effective than using computer assisted instruction with mastery learning. This study will add to the literature because no other study has compared the results on achievement of developmental students taught using mastery learning supplemented by a computer 
assisted instruction (MyMathLab) and students taught using computer assisted instruction without mastery learning.

However, it should be noted that a study reviewed in Chapter 2 compared the impact of computer assisted mastery learning (CML) versus computer assisted cooperative learning (CCL) on solving matrices in high school. Hoon et al. (2010) found that low academic ability high school students' gain scores were significantly better for those taught using computer assisted mastery learning than those taught using computer assisted cooperative learning (GainScores ${ }_{\mathrm{CML}}>$ GainScores $_{\mathrm{CCL}}$ ). Although this study and Hoon et al.'s differed in the fact that I did not use cooperative learning, the two studies shared common elements: Mastery learning, time on task and their impact on the achievement of struggling math students. Hoon et al.'s study showed a difference in gain scores, while my study found no difference in adjusted mean final exam scores but a higher passing rate for students in group A. The studies are not exactly equivalent, but both found some benefit to struggling students using mastery learning.

Hypothesis 2. There was a significant difference in the adjusted means of final examination scores of students who were taught using mastery learning coupled with MML and those students who were taught without MML or mastery learning (Group A vs. Group C). Students in Group A scored higher than those in Group C. Hence, the null hypothesis $\left(\mathrm{H}_{02}\right)$ was rejected. This finding was consistent with earlier research on the impact of mastery learning supplemented by computer assisted instruction (Abadir, 1993; Guskey \& Gates, 1985; Kulik, J., Kulik, C., \& Bangert, 1990). These study results concerning combination of mastery learning techniques coupled with computer assisted 
instruction seemed to suggest this combination of teaching strategies should be considered by instructors teaching developmental mathematics in postsecondary education.

Hypothesis 3. There was no significant difference in the adjusted means of final examination scores among students who were taught using MML in the absence of mastery learning and students who were taught without MML or mastery learning techniques (Group B vs Group C). Therefore, the null hypothesis $\left(\mathrm{H}_{03}\right)$ was not rejected. This finding is consistent with earlier research by Spradlin (2009) and by Li and Edmonds (2005) who also found no significant difference among students who were taught using traditional instruction supplemented by computer assisted instructor and student who were taught using traditional instruction only.

Hypothesis 7. Hypothesis 7 is included here because, like the first three hypotheses, it concerns differences in means rather than proportions like the latter three. Caroll's (1963) work on a theory of mastery learning, which lists five characteristics of mastery learning, indicates that three of these are related to time. Therefore, in this study a measure of time on task was defined as the number of minutes students spent in tutored situations or were logged in to the homework section of MyMathLab. When time on task was added as a second covariate in the previously described ANCOVA where pretest score was the sole covariate, the procedure revealed no significant difference between the adjusted means of final examination scores, adjusted for pretest score and time on task, of students who were taught using each of the three treatments. Therefore, the null hypothesis $\left(\mathrm{H}_{07}\right)$ was not rejected (see Table 12). This differs from the results of testing 
the overall null hypothesis that the mean posttest scores adjusted for the pretest scores were equal within all three groups. The time on task appears to have removed the effect due to treatment. Participants in Group A, the only group that was taught using mastery learning, were able to take advantage of additional reinforcement through extra exercises for those who did not meet $70 \%$ accuracy in any chapter assignment conducted under the guidance of their instructors. This suggests that MyMathLab may be efficacious because it allows for appropriate time on task using mastery learning. Further, the data suggest that teachers of developmental mathematics should try to use mastery learning techniques in their classrooms.

An interesting note to the discussion of time on task is that there was a significant difference in the amount of time on task between groups $(F=32.307, d f=1$, $\left.168, p<.001, \eta^{2}=.161\right)$. Tests for paired groups showed that the average time on task for students in Group A was greater than the average time on task in Group B, which was greater than the average time on task for Group $C\left(\mu_{A}>\mu_{B}>\mu_{C}\right)$. This phenomenon supports the notion above that suggests that students taught using mastery learning tend to spend more time on their assignments. This is important, because as Hoon et al. (2010) pointed out in their study, "quality was the key to making time matter" (p. 129). They continued, "Students should be provided with activities and instructions that catered to their needs and abilities, engaging them so they would continue to build on what they had learnt."

Hypothesis 4. A chi-square analysis was conducted to determine whether there was a significant difference in frequency of passing status. The variable "passing status" 
had three values (pass, failed and withdraw). It was found that the method of instruction among the three groups had a significant effect on the passing status. Further tests were conducted to analyze the pairwise difference among groups. It was found that there was no significant difference in method of instruction and passing status on two levels (fail and withdraw); however, there was a significantly different proportion of students who passed the course who were taught using mastery learning coupled with MML when compared to students who were taught using MML in the absence of mastery learning. Therefore the null hypothesis $\left(\mathrm{H}_{04}\right)$ was rejected (Group A vs. Group B). Students in Group A had a higher passing rate than those in Group B.

Hypothesis 5. The pairwise difference analysis of the method of instruction and passing status revealed significant difference on all three levels (pass, fail and withdraw) among students who were taught using mastery learning supplemented by MML and students who were taught without either mastery learning or MML. Hence the null hypothesis $\left(\mathrm{H}_{05}\right)$ was rejected (Group A vs. Group C). Students in Group A had the higher passing rate and the lower failing and withdrawal rates than those in Group C.

Hypothesis 6. Finally, the last pairwise comparison analysis revealed no significant difference on the method of instructions and the proportion of students who failed or withdrew from the class. However, there was a significant difference on the proportion of students who passed the course who were taught using MML in the absence of mastery learning and students who were taught without MML or mastery learning. Therefore the null hypothesis $\left(\mathrm{H}_{06}\right)$ was rejected (Group B vs. Group C). Students in Group B had a higher passing rate than those in Group C. 
The findings in the research questions 4, 5 and 6 were consistent with earlier study by Boggs and Shore (2004) that found a higher passing rate for students who used computer assisted instruction. Specifically concerning the use of MyMathLab, Kodippili and Senaratne (2008) assigned homework exercises to college algebra students in efforts to compare and measure the efficacy of using MyMathLab on line homework versus traditional paper-based, instructor-graded homework to help students learn mathematics. They found that students who used MyMathLab to do their homework had significantly higher success rates than the students who used paper based homework. They attributed the difference in success rate to some of the features MyMathLab offered such instant feedback, repetition, videos and easy access from any computer with Internet access.

Discriminant function analysis. The ability of time on task to predict the passing status of students was tested using a discriminant function analysis with time on task and pretest score as predictor variables. Based on the classification results, $89 \%$ of participants were correctly classified and $26.41 \%$ of the variability in passing status was due to time on task. This finding was consistent with Caroll's (1963) model of school learning that introduced five variables for students' success, three of which were related to time (aptitude, opportunity to learn, and perseverance). He claimed that when students are given the time needed to work on a given topic, if they persist, they should reach the "criterion level of achievement".

When the pretest scores were added as the second predictor, the classification results showed that $94 \%$ of students were correctly classified and that $58 \%$ of the variability on passing status was due to time on task and the pretests scores. This implies 
that when time on task and pretest scores were used together as predictors of passing status, the classification results were more reliable than just time on task alone.

Furthermore, it may indicate that the knowledge students bring in to post-secondary education is responsible for a greater proportion of student success than most teaching strategies being used in developmental mathematics in higher education. This is why many are recommending high schools to better prepare students so that they can avoid being placed into developmental mathematics. This will increase students' chances to graduate college and it will eliminate the expense of developmental education in higher education (Barnett \& Fay, 2013). Students' success in college will depend on their high school preparation and not on developmental mathematics in post-secondary education.

\section{Implications}

\section{Implications for Practice}

Knowles (1984) claimed that adult learners are self-directed and take responsibility for their own actions. Furthermore, they are likely to engage in their learning process, and they are task motivated. Also, adult learners expect a closer working-relationship between faculty members and students (Kenner, 2011). MyMathLab provided adult learners in this study the opportunity to strengthen and/or develop those qualities and expectations mentioned by Knowles and by Kenner. MyMathLab made it easier for students and instructors to communicate through a chatroom or discussion boards; hence fostering a virtual-working-relationship between faculty and students. In informal discussions with me, the instructors in this study reported that students who used MML were more engaged with their instructors and 
classmates using MML chat-rooms and/or discussion boards than they were in classroom activities. In addition, MML facilitated students having plenty of time to learn new material through repetition, created a non-threatening learning environment through chatrooms and used a multi-sensory method for learning through videos and animations about how to solve a mathematics problem. All of these strategies were consistent with some of the recommendations put forward by Murk (1994) on how to teach adult learners.

In this study students in group A were taught using mastery learning supplemented by MML and students in group B were taught using MML in the absence of mastery learning. MML offered students in both groups instant feedback on homework questions. Some other features available to both groups included in the homework section were: (a) view an example, (b) help me solve this problem, (c) connect to a MML tutor, and (d) videos. These features offered by MyMathLab may have been the reasons why students in groups A and B spent more time on task than student in group C, who had no access to MML.

Moreover, it was noticed that students in group A spent more time logged in to MML then students in group B. One of the reasons may have been that students in group A were taught using mastery learning coupled with MML. Part of mastery learning technique was that students had to take a pretest after the end of each chapter to show mastery. This allowed instructors to assigned extra homework for those who did not achieved a mastery level of least $70 \%$ in a particular chapter without penalizing the rest of the students. Furthermore, instructors in the study observed homework completion was the highest among students taught using mastery learning supplemented by MyMathLab 
then students in groups B and C. This may explained why students in group A had a significantly higher passing rate than those in groups B and C.

\section{Implications for Policy}

As the number of mathematically unprepared students continues to grow in colleges and universities across the United States, the need for developmental mathematics courses will continue to play an important role in the future of the workforce, especially in STEM related jobs. Developmental education is important, as Boylan (2009) stated, "Postsecondary institutions must serve the students they have, not those they wish they had, and they must serve these students through some sort of developmental education" (p. 20). Institutions of higher education and faculty members must search for teaching and learning strategies that address the need of students enrolled in developmental courses, especially those in developmental mathematics courses. It is has been well documented that these students do not well in developmental mathematics course where they are taught only through traditional instruction method (Boylan \& Saxon, 2002; Roueche \& Kirk, 1974). Unfortunately, some colleges, and universities and their faculty members continue to teach students enrolled in developmental mathematics courses using traditional instruction as the only method of instruction, hence putting thousands of students at a disadvantage. When students do not do well in developmental courses, it delays their graduation by one or two years, costing taxpayers millions of dollars (Bailey \& Cho, 2010).

On the other hand, there are institutions in higher education that have invested a great deal of money and human resources to find a solution to high attrition and low 
passing rates among students in developmental education, especially in developmental mathematics. A great deal of research has been done to find efficacious teaching and learning strategies in developmental mathematics. The search for better teaching and learning strategies has produced studies with mixed results. Among possible solutions to this problem is the use of computer assisted instruction. Over decades, hundreds of studies have been conducted and designed to investigate the efficacy of computer assisted instruction among students in developmental mathematics courses. Some researchers have found that computer assisted instruction, when used as the only method of instruction, does not serve developmental students well because they tend to withdraw from those courses at a higher rate versus students who enroll in classes where they have access to an instructor (Zavarella \& Ignash, 2009). However, a possible solution to high withdrawal and low passing rates among students in developmental mathematics courses is not to use computer assisted instruction to replace traditional instruction but rather to use computer assisted instruction as a supplement to traditional instruction. According to Cotton (1991), students in developmental mathematics perform significantly better when computer assisted instruction is used to supplement traditional instruction versus a teaching method where either computer assisted instruction or traditional instructors are used alone.

In this study, I found that the proportion of students who passed MAT1033 was significantly higher when students were taught using traditional instruction with mastery learning coupled with computer assisted instruction versus students who were taught with traditional instruction coupled with computer assisted instruction without mastery 
learning. In addition, this study revealed significant higher adjusted posttest means, higher passing rate, lower failing and lower withdrawal rate when students were taught using traditional instruction using mastery learning coupled with computer assisted instruction versus students who were taught using traditional instruction only. Mastery learning coupled with computer assisted instruction to supplement traditional instruction could be the solution to low academic performance and high withdrawal rate among students in developmental mathematics course in higher education. According to Bonham $\&$ Boylan (2011), there are many projects underway to improve the overall success among students enroll in developmental mathematics courses but they argue, "that in order to see a significant improvement, institutions in higher education, policy makers and developmental mathematics instructors must collaborate in changing the way developmental mathematics is structured, taught, and delivered" (p. 8). Now it is up to policy makers to find ways to keep and continue to fund developmental education, especially developmental mathematics in higher education.

\section{Recommendations for Future Research}

This study examined theoretically based hypotheses regarding mastery learning and computer assisted instruction with adult students (Bloom, 1968; Knowles, 1984; Knowlton \& Simms, 2009) enrolled in a developmental mathematics course, MAT1033, at a 4-year state college. Based on my findings, I have four recommendations for future research. The first one is for this study to be replicated with students enrolled in a college credit-bearing mathematics class using qualitative and quantitative methodologies. It is crucial to obtain feedback on students' experiences using MyMathLab. Which features do 
students find more appealing? Is the instant feedback on homework exercises they like more? Or do students find the short videos helpful? Do students like the pretest approach as one of the mastery learning strategies? Software developers can use this feedback to improve the current software. Instructors can also use the feedback to better select and use particular features of software for developmental classes. In addition, it will be important to document and analyze what features of MyMathLab are more effective for students' overall success.

Second, it is important to replicate the study comparing other software such as Mathzone, Connectmath or ALEK. It will be of great value to know which of these software students welcome best, more importantly, which of these software programs is better for mastery learning and computer assisted instruction. MyMathLab is not an adaptive system which meant that instructors in this study had to create extra homework and prestests and posttests, using MyMathLab, for each student who did not meet the minimum criterion for mastery learning. This was a daunting task for instructors to have to do. Other software programs, which are adaptive in nature, may facilitate teaching using mastery learning techniques for instructors.

Third, it is for this study to be replicated using part-time and full time instructors. There was no significant difference in passing status among the three full time instructors in this study. It is important to find out if the same outcomes will be seen with part time faculty. This is important to find out because part-time faculty members form almost half of the faculty in institutions of higher learning (National Center for Education Statistics, 2012). Typically they are responsible for teaching a large proportion of post-secondary 
developmental and other lower level courses. As noted previously, most of the current teaching strategies are not benefiting students in developmental mathematics; it has been well documented that only $30 \%$ succeed. The success in developmental mathematics will depend in the effective training and participation of all faculty members, especially part time instructors. The findings of this study suggest that the integration of mastery learning coupled with computer assisted instruction to supplement traditional instruction should be considered by those teaching college students who are enrolled in developmental mathematics. Replicating this study with part-time instructors will provide valuable feedback for their professional development to enhance their ability to meet developmental students' needs.

The last recommendation is for a study to incorporate supplemental instruction and mastery learning supplemented by computer assisted instruction. Incoming students who are placed into developmental mathematics course, for the most part, have poor study behavior and poor study skills. Furthermore, developmental mathematics course have high attrition rate and are leveled as "At risk" courses. Supplemental instruction includes scheduling after class, peer facilitated study sessions to discuss and assist students learning the material for at risk courses (Martin, Lorton, Blanc, \& Evans, 1977).

\section{Summary}

This study analyzed the efficacy of mastery learning supplemented by computer assisted instruction on achievement of developmental students enrolled in MAT1033. The study took place at Miami Dade College, Homestead Campus, Homestead, Florida. Seven sections of MAT1033 were selected for the study. Three different treatments 
groups were formed: (a) Students in group A who were taught using mastery learning coupled with MyMathLab, (b) students in group B who were taught using MyMathLab in the absence of mastery learning, and (c) students in groups $\mathrm{C}$ who were taught without MyMathLab or mastery learning. All three groups were taught using traditional instruction method. A one-way analysis of covariance revealed that there was a significant difference in the adjusted final examination means of students in group A and students in group $\mathrm{C}$ such that group A had a higher mean final examination score; no significant difference was found between groups $\mathrm{A}$ and $\mathrm{B}$, and no significant difference was found between B and C. Moreover, a chi-square test revealed a significant difference in passing status on all three levels (pass, fail and withdraw) between students in group A and students in group C. Again, group A had a higher passing rate and lower failing and withdrawal rates. The rest of pairwise comparisons revealed a significant difference on passing status in one level, passing. This means that mastery learning supplemented with MyMathLab had a significant effect on overall performance of developmental students.

Time on task (time spent logged in to the homework section of MML or at the tutoring laboratory) and pretests turned out to be good predictors for group membership (passed or failed). The classification results in the discriminant function analysis showed that $89 \%$ of students were correctly classified when time on task was used a predictor. When the pretest (pre-treatment) scores were added as a second predictor, the classification results increased the probability of an accurate prediction from $89 \%$ to $94 \%$ on the passing status. The time students spent engaged in learning class content and their 
mathematics knowledge they had coming into this class both played an important part in whether students passed or failed MAT1033.

Last, tests for paired groups revealed that students in Group A spent more time on task than students in Group B, which in turn was greater than the time students in Group $C$ spent on task $\left(\mu_{A}>\mu_{B}>\mu_{C}\right)$. This suggests that mastery learning techniques supplemented by MyMathLab were helpful on motivating students to do their assignments. 


\section{REFERENCES}

Abadir, L. (1993, April). Effects of mastery learning strategies on community college mathematics students' achievement and success rate. Paper presented at the Annual Meeting of the American Education Research Association, Atlanta, GA. Retrieved from ERIC database. (ED358167)

Aichele, D. B., Francisco, C., Utley, J., \& Wescoatt, B. (2011). Computer-aided college algebra: Learning components that students find beneficial. MathAMATYC Educator, 2(2), 12-19.

Aycaster, P. W. (2001). Factors impacting success in community college developmental mathematics courses and subsequent courses. Community College Journal of Research and Practice, 25, 403-416.

Bailey, T. (2008). Challenge and opportunity: Rethinking the role and function of developmental education in community college. CCRC working paper no.14. Community College Research Center, Teachers College, Columbia University. Retrieved from http://ezproxy.fiu.edu/login?url=http://search.proquest.com/docview/61899508?ac countid=10901

Bailey, T., \& Cho, S. (2010). Issue brief: Developmental education in community colleges .Community College Research Center, Teachers College, Columbia University. Retrieved from http://ezproxy.fiu.edu/login?url=http://search.proquest.com/docview/815957829? accountid=10901

Barnett, E. A., \& Fay, M. P (2013). The Common core state standards: Implications for community colleges and students preparedness for college. National Center for Postsecondary Research. Retrieved from http://www.postsecondaryresearch.org/i/a/document/25958 common-core-statestandards_2.pdf

Bashford, J. (2005). Information Capsule NO.04-05C. Miami-Dade College, Institutional Research, Miami, FL.

Bashford, J. (2006). Information Capsule NO.06-07C. Miami-Dade College, Institutional Research, Miami, FL...

Bloom, B. S. (1968). Learning for mastery. Evaluation Comment (UCLA-CSIEP), 1(2), $1-12$.

Bloom, B. S. (1974). Time and learning. American Psychologist, 29, 682-688. 
Bloom, B. S. (1984). The 2 sigma problem: The search for methods of group instruction as effective as one-to-one tutoring. Educational Researcher, 13(6), 4-16.

Boggs, S., Shore, M., \& Shore, J. (2004). Using e-learning platforms for mastery learning in developmental mathematics courses. Mathematics and Computer Education, 38, 213-220.

Bonham, B. S., \& Boylan, H. R. (2011). Developmental mathematics: Challenges, promising practices, and recent initiatives. Journal of Developmental Education, $36(2), 14-21$.

Boylan, H.R. (2002). What works: Research-based best practices in developmental education. Boone, NC. Continuous Quality Improvement Network with the National Center for Developmental Education.

Boylan, H.R. (2009). Target Intervention for Developmental Education Students (T.I.D.E.S). Journal of Developmental Education, 32(3), 14-23.

Boylan, H. R., \& Saxon, D. (2002). What works in remediation: Lessons learned from 30 years of research. Boone, NC: Appalachian State University, National Center for Developmental Education.

Burch, K., \& Kuo, Y. (2010). Traditional vs. online homework in college algebra. Mathematics and Computer Education, 44, 53-63.

Business-Higher Education Forum. (2005, January). A commitment to America's future: Responding to the crisis in mathematics and science education. Retrieved from http://www.bhef.com/publications/documents/commitment future 05.pdf

Business-Higher Education Forum. (2011a, November). Meeting the STEM workforce Challenge: Leveraging higher education's untapped potential to prepare tomorrow's STEM workforce. Retrieved from http://www.bhef.com/publications/documents/BHEF_Policy_BriefSTEM Workforce_Challenge.pdf

Business-Higher Education Forum. (2011b, October). Meeting the STEM workforce demand: Accelerating math learning among students interested in STEM. Retrieved from http://www.bhef.com/publications/documents/BHEF Research_BriefAccelerating Math Learning.pdf 
Business-Higher Education Forum (2012, May). STEM interest among college students: Where they enroll. Retrieved from http://www.bhef.com/publications/documents/BHEF_Research_BriefSTEM_Interest_Among_College_Students.pdf

Capper, J., \& Copple C. (1985). Computer use in education: Research review and instructional implications. Washington, DC: Center for Research into Practice.

Carroll, J. B. (1963). A model of school learning. Teachers College Record, 64, 723-733.

Carroll, J. B. (1989). The Carroll model: A 25-year retrospective and prospective view. Educational Research, 18, 26-31.

Clark, C. M., \& Caffarella, R. S. (1999). Theorizing adult development. New Directions for Adult and Continuing Education, 84, 3-7. Retrieved from http://ezproxy.fiu.edu/login?url=http://search.proquest.com/docview/62416061?ac countid=10901

Contreras, F. E. (2005). Access, achievement, and social capital: Standardized exams and the Latino college-bound population. Journal of Hispanic Higher Education, 4, 197-214.

Cotton, K. (1991, May). Computer-assisted instruction. Northwest Regional Educational Laboratory, School Improvement Research Series. Retrieved from http://www.nwrel.org/scpd/sirs/5/cu10.html

Cross, K. P. (1981). Adult learners. San Francisco, CA: Jossy-Bass.

Cullinane, J., \& Uri, P. (2010). Improving developmental mathematics education in community colleges: A prospectus and early progress report on the Statway Initiative. (An NCPR Working Paper). Retrieved from http://www.postsecondaryresearch.org/conference/PDF/NCPR_Panel4_Cullinane TreismanPaper_Statway.pdf

Estrine, L. (1975). Assessment of computer assisted instruction as tool for advancing adult learning. Retrieved from ERIC database. (ED140073)

Ford, B., \& Klicka, M. A. (1998). The effectiveness of individualized computer assisted instruction in basic algebra and fundamentals of mathematics courses. Retrieved from ERIC database. (ED428962)

Frey, R. (2007). Helping adult learners succeed: Tools for two-year colleges. Council for Adult and Experiential Learning. Retrieved from http://ezproxy.fiu.edu/login?url=http://search.proquest.com/docview/742875663? accountid=10901 
Galbraith, M. W. (2002/2003). The adult education professor as mentor: A means to enhance teaching and learning. Perspectives: The New York Journal of Adult Learning, 1(1), 9-20.

Hawkins, E., Stancavage, F., \& Dossey, J. (1998). School policies and practices affecting instruction in mathematics: Findings from the National Assessment of Education Progess. American Institute for Research. Washington, DC: National Center for Education Statistics.

Hodara, M. (2011). Reforming mathematics classroom pedagogy: Evidence-based findings and recommendations for the developmental classroom. CCRC working paper no. 27. Community College Research Center, Teachers College, Columbia University.

Hoon, T. S., Chong, T. S., \& Binti Ngah, N. A. (2010). Effect of an interactive courseware in the learning of matrices. Educational Technology \& Society, 13(1), $121-132$.

Hornbeck, D. W. (1990). Technology and students at risk of school failure. Retrieved from ERIC database. (ED327175)

John-Streiner, V. \& Mahn, H. (2003). Sociocultural contexts for teaching and learning. In W. Reynolds, \& G. Miller (Eds.), Handbook of educational psychology, Volume 7 (pp. 125-147). Hoboken, NJ: Wiley.

Keller, F. S. (1968). Goodbye teacher. Journal of Applied Behavior Analysis 1, 79-89.

Kenner, C., \& Weinerman, J. (2011). Adult learning theory: Applications to nontraditional college students. Journal of College Reading and Learning, 41, 87-96.

Knowles, M. S (1974). Human resources development OD. Public Administration Review, 34, 115-123.

Knowles, M. S. (1984). Andragogy in action. San Francisco, CA: Josey-Bass.

Knowlton, D. S., \& Simms, J. (2009). Generative strategies and computer-based instruction for teaching adult students. TechTrends: Linking Research and Practice to Improve Learning, 53(3), 54-60.

Kodippili, A., \& Senaratne, D. (2008). Is computer generated interactive mathematics homework more effective than traditional instructor-graded homework? British Journal of Education Technology, 39, 929-932.

Kulik, C., \& Kulik, J. A. (1985). Effectiveness of computer-based education in colleges. Retrieved from ERIC database. (ED263890) 
Kulik, C., \& Kulik, J. (1991). Effectiveness of computer-based instructions: An updated analysis. Computers in Human Behavior, 7, 75-94.

Kulik, C., Kulik, J., \& Bangert-Drowns, R. (1990). Effectiveness of mastery learning programs: A meta-analysis. Review of Educational Research, 60, 265-299.

Kulik, J. (2002). School mathematics and science programs benefit from instructional technology. Retrieved from ERIC database. (ED472100)

Kulik, J., Kulik, C., \& Cohen, P. (1980). Effectiveness of computer-bases college teaching: A meta-analysis of findings. Review of Educational Research, 50, 525 544.

Li, Q., \& Edmonds, K. A. (2005). Mathematics and at-risk adult learners: Would technology help? Journal of Research on Technology in Education, 38, 143-166.

Liao, Y. K. C. (2007). The effects of computer-assisted instruction on students' achievement in Taiwan: A meta-analysis. Computers and Education, 48, 216-233.

Lin, C. H., Liu, E. Z. F., Chen Y. L., Liou, P. Y., Chang, M., Wu, C. H., Yuan, S. M. (2013). Game-based remedial instruction in mastery learning for upper-primary school students. Educational Technology \& Society, 16, 271-281.

Lu, Y. (2011). Using a virtual classroom to teach online mathematics. Retrieved from ERIC database. (ED519767)

Mahmood, S. J. (2006). Examining the mathematics performance of developmental mathematics students when computer-assisted instruction is combined with traditional strategies. Texas Southern University. ProQuest Dissertations and Theses, 90. Retrieved from http://ezproxy.fiu.edu/login?url=http://search.proquest.com/docview/304957177? accountid=10901. (304957177).

Martin, D. C., Lorton, M., Blanc, R. A., \& Evans, C. (1977).The learning center: A comprehensive model for colleges and universities. Grand Rapids, MI: Aquinas College. Retrieved from ERIC database. (ED162294)

Mathematics Association of America. (n.d.). http://www.maa.org

Murk, P. J. (1994). Learning styles and lessons from the medicine wheel: A Native American philosophy, a proposed integrated model. Retrieved from the ERIC database. (ED378387)

National Center for Education Statistics. (2002). Special analysis 2002: Nontraditional undergraduates. Retrieved from

http://nces.ed.gov/programs/coe/2002/analyses/nontraditional/sa01.asp 
National Center for Education Statistics. (2012). Digest of education statistics. Retrieved from http://nces.ed.gov/programs/digest/d12/

Penny, M., \& White, W. (1998). Developmental mathematics students' performance: Impact of faculty and student characteristics. Journal of Developmental Education 22(2), 2-9.

Perle, M., Moran, R., Lutkus, A. D., \& Tirre, W. (2005). NAEP 2004 trends in academic progress: Three decades of student performance in reading and mathematics. Washington, DC: National Center for Education Statistics.

Pearson Publishing (2013). MyMathLab features. Retrieved from http://www.MyMathLab.com/MyMathLab-features

Pousa, A. (2014). Profile demographics, Fall 2013. Miami Dade College, Institutional Research. Retrieved from http://www.mdc.edu/ir/datapages/profile_fallfall/profile_fallfall_HOMESTEAD CREDIT 2013.html

Rapaport, R., \& Savard, W. G. (1980, December). Computer-assisted instruction. Research on school effectiveness project: Topic summary report. Portland, OR: Northwest Regional Educational Laboratory. Retrieved from ERIC database. (ED214707)

Rodriguez, S. (2011). Information Capsule No. 2011-07C. Miami Dade College, Institutional Research, Miami, FL.

Rodriguez, S. (2012). Placement test results for first time in college students. Miami Dade College, Institutional Research. Retrieved from https://www.mdc.edu/ir/iremployees/2011_Placement_Test_FTIC.pdf

Roueche, J. E., \& Kirk, R. W. (1973). Catching up: Remedial education. San Francisco, CA: Jossey-Bass.

Schwartz, A. E. (2007). New standards for improving two-year mathematics instruction. Education Digest: Essential Readings Condensed for Quick Review, 73(2), 39-42.

Skinner, B. F. (1968). The technology of teaching. New York, NY. Appleton-CenturyCrofts.

Sosa, G. W., Berger, D. E., Saw, A. T., \& Mary, J. C. (2011). Effectiveness of computerassisted instruction in statistics: A meta-analysis. Review of Educational Research, 81, 97-128. 
Sowell, R. (2011). Use of mastery learning using MyMathLab. Retrieved from http://www.MyMathLab.com/case-study/1399/volunteer-state-communitycollege- 0

Spradlin, K. D. (2009). The effectiveness of computer-assisted instruction in developmental mathematics. (Liberty University). ProQuest Dissertations and Theses, 161.Retrieved from http://ezproxy.fiu.edu/login?url=http://search.proquest.com/docview/305134311? accountid=10901. (305134311).

Stokes, S. D. (2011).A multi-metric assessment on the impact of I can LearnRTM(ICL) multimedia on actual and perceived student achievement in developmental mathematics. (Southern University and Agricultural and Mechanical College). ProQuest Dissertations and Theses, 187.Retrieved from http://ezproxy.fiu.edu/login?url=http://search.proquest.com/docview/868529286? accountid=10901. (868529286)

Suppes, P., \& Morningstar, M. (1969). Evaluation of three computer-assisted instruction programs Retrieved from http://ezproxy.fiu.edu/login?url=http://search.proquest.com/docview/64405537?ac countid=10901

Tinto, V. (1987, November). The principles of effective retention. Paper presented at the Fall Conference of the Maryland College Personnel Association, Largo, MD. Retrieved from ERIC database. (ED301267)

Trochim, W. M. (2006). The research methods knowledge base (2nd ed.). Englewood, CO: Dream Books. Retrieved from http://www.socialresearchmethods.net/kb/

U.S. Department of Commerce (2011, July). STEM: Good jobs now and for the future. Economics and Statistics Administration. Retrieved from http://www.esa.doc.gov/sites/default/files/reports/documents/stemfinaljuly14.pdf

Vezmar, K. A. (2011). Analyzing the effects of MyMathLab on student achievement in elementary algebra. (University of Delaware). ProQuest Dissertations and Theses, 64.Retrieved from http://ezproxy.fiu.edu/login?url=http://search.proquest.com/docview/884210489? accountid=10901. (884210489)

Villarreal, L. (2003). A step in the positive direction: Integrating a computer laboratory component into developmental algebra courses. Mathematics and Computer Education, 37, 72-78.

Winn, W. (1995). Advantages of a theory-base curriculum in instructional technology. Retrieved from the ERIC database. (ED38112) 
Zavarella, C. A., \& Ignash, J. M. (2009). Instructional delivery in developmental mathematics: Impact on retention. Journal of Developmental Education, 32(3), 213. 
VITA

\title{
JEFFREY MIRANDA
}

\author{
$1997-2000$ \\ B.S., Mathematics \\ Florida International University \\ Miami, Florida \\ 2001-2003 \\ M.S., Mathematics \\ University of Miami \\ Miami, Florida \\ 2003-Present \\ Associate Professor \\ Miami Dade College \\ Miami, Florida \\ 2002-2003 \\ Teaching Assistant of the Year Award \\ University of Miami \\ Miami, Florida \\ $2005-2009$ \\ M.S., Higher Education Administration \\ Florida International University \\ Miami, Florida \\ 2009-2014 \\ Doctoral Candidate \\ Florida International University \\ Miami, Florida
}

